\title{
Effects of Diatomite and SBS on Freeze-Thaw Resistance of Crumb Rubber Modified Asphalt Mixture
}

\author{
Haibin Wei, Ziqi Li, and Yubo Jiao \\ College of Transportation, Jilin University, Changchun 130025, China \\ Correspondence should be addressed to Yubo Jiao; jiaoyb@jlu.edu.cn
}

Received 20 February 2017; Revised 26 April 2017; Accepted 30 April 2017; Published 21 May 2017

Academic Editor: Gianluca Cicala

Copyright (C) 2017 Haibin Wei et al. This is an open access article distributed under the Creative Commons Attribution License, which permits unrestricted use, distribution, and reproduction in any medium, provided the original work is properly cited.

\begin{abstract}
Asphalt mixture is susceptible to moisture damage under the effect of freeze-thaw (F-T) cycles. In this paper, crumb rubber (CR) was used to modify stone mastic asphalt (SMA) and the effects of diatomite and styrene butadiene styrene (SBS) on antifreezing performances of crumb rubber modified SMA (CRSMA) were investigated. Regression analysis and modified grey model (MGM) were used to construct the prediction models for properties of modified mixtures. CRSMA, CR and diatomite modified SMA (CRDSMA), and CR and SBS modified SMA (CRSSMA) were prepared in laboratory, respectively. Process of F-T cycles was designed. Air void, indirect tensile strength (ITS), and indirect tensile stiffness modulus (ITSM) were measured to evaluate the antifreezing performances of CRSMA, CRDSMA, and CRSSMA. Results indicate that air voids increase with the increasing of F-T cycles. ITS and ITSM all decrease with the increasing of F-T cycles. The addition of diatomite and SBS can reduce the air void and improve the ITS and ITSM of CRSMA. CRSSMA presents the lowest air void, highest tensile strength, and largest stiffness modulus, which reveals that CRSSMA has the best F-T resistance among three different kinds of mixtures. Moreover, MGM $(1,2)$ models present more favorable accuracy in prediction of air void and ITS compared with regression ones.
\end{abstract}

\section{Introduction}

Reuse of waste materials can reduce the consumption of natural resources. Moreover, it can alleviate the waste accumulation, which can cause serious environmental problem [1-3]. Therefore, reuse of waste materials has got great attention. With the rapid development of automotive industry, the number of vehicles increases, and then amount of scrap tires also increases. According to the statistical data, over 1 billion tires are sold each year all around the world and millions of waste tires are generated $[4,5]$. Waste tires are not easily disposed of and lead to great threat to public health and environment. Many solutions have been proposed for reuse of scrap tires [6-9].

Scrap tires can be recycled in the form of crumb rubber (CR), which is a profitable practice. La Rosa et al. [9] demonstrated that the addition of $50 \mathrm{phr}$ of ground tire rubber (GTR) in styrene-isoprene-styrene (SIS) formulation presents favorable environmental benefits. Life cycle assessment (LCA) results indicate that the effects of virgin rubber (47.1\%) and carbon black (34.3\%) on environmental impacts of GTR are more obvious than tire grinding process $(4 \%)$. Farina et al. [10] investigated the environmental performance of using crumb rubber in bituminous mixtures based on LCA. Results reveal that asphalt rubber obtained through wet process presents significant benefits for energy saving, environmental impact, human health, preservation of ecosystems, and minimization of resource depletion. The reductions of gross energy requirement and global warming potential range between $36 \%$ and $45 \%$ compared with standard paving solutions. Furthermore, CR can be used to modify asphalt, which is an effective method to consume them. Previous researches have demonstrated that CR is a successful modifier for asphalt mixture because of favorable compatibility and interaction between rubber and asphalt [5]. CR modified asphalt and mixture have many advantages. They can improve the rutting resistance at high temperature, crack resistance at low temperature, fatigue resistance, and elastic performance $[4,11-13]$. Moreover, Liang et al. [14] investigated the viscous properties, storage stability, and morphology of recycled tire scrap rubber modified asphalt (TSRMA). The results reveal that the addition of crumb rubber can increase viscosity of 
asphalt and improve rutting deformation resistance. However, it presents poor stability with the increasing of rubber particle size. Navarro and Gámez [4] presented the effect of crumb rubber on bearing capacity and cohesion of asphalt mixture. The results show that crumb rubber can increase the stiffness and stability of mixture, while it slightly reduces tensile strength. De Almeida Júnior et al. [15] evaluated the properties of asphalt modified by rubber and styrene butadiene styrene (SBS), respectively. The findings indicate that rubber has the potential performance to substitute SBS in pavement materials. However, it does not meet some of the requirements in standard specifications.

Diatomite is a widely used mineral with low cost and considerable storage, which has high absorptive capacity and stability [16-22]. It has been widely used for asphalt modification in China [16-21]. Mohamed Abdullah et al. $[17,18]$ studied the properties of diatomite modified asphalt. The results indicate that there is no chemical reaction between asphalt and diatomite. Diatomite can improve the rutting resistance of asphalt at high temperature. The aging resistances of modified asphalt are superior to pure one. Cheng et al. [19] demonstrated the antiaging properties of diatomite modified asphalt. The results reveal that diatomite is helpful for improving the high temperature stability and antiaging property of asphalt. Tan et al. [21] investigated the low temperature property of diatomite modified asphalt. The results show that diatomite particles distribute well in asphalt and diatomite modified mixture possesses better low temperature performance than neat one.

Currently, SBS copolymer is the most widely used modifier for asphalt, which can absorb the oil fractions and swell them [23-25]. It can improve both high and low temperature performances of mixture. Khodaii and Mehrara [26] conducted dynamic creep tests for unmodified and SBS modified asphalt. SBS modified mixture possesses lower temperature susceptibility and higher compactibility. Sun et al. [27] found that reactive blending of SBS and asphalt can improve the hot storage stability, rheological properties, elasticity, and deformation resistance of modified asphalt. The limitations for SBS modified asphalt lie in its lower workability, higher production cost, and being easy to aging $[28,29]$. Therefore, it is crucial to have some other waste materials to partially substitute for SBS in modified asphalt. CR can reduce the cost and possess favorable performances, which is a favorable substitute. In order to meet the requirements of high grade road pavement, modified asphalt with better performances can be prepared using CR and SBS composite modifier. Dong et al. [30] investigated the rheological behavior of SBS/CR composite modified asphalt. The results reveal that the addition of $\mathrm{CR}$ and SBS can effectively improve the viscoelastic property and temperature sensitivity of asphalt.

In addition, freeze-thaw (F-T) cycle is an important factor to influence the performances of road pavement in seasonal frozen regions, which cover $53.5 \%$ of China's land area. Road pavement in this region is exposed to at least one F-T cycle each year [31]. CR has been widely used in concrete to provide F-T protection [32]. Meanwhile, Zhang et al. [33] found that rubber modified asphalt mixture has better antifreezing performance than the neat one. Current research results indicate that $\mathrm{CR}$ is an effective additive to improve the F-T resistance for road materials.

Grey theory was proposed by Deng in 1982 [34], which had been widely used in many fields for factor analysis and forecasting. Grey relational analysis (GRA) was widely used to evaluate the influential degrees of factors $[35,36]$. Grey model is another important aspect in grey theory, which can achieve high prediction accuracy for uncertain systems. It can realize the prediction of system behavior using fewer data and less complicated mathematical calculation [37]. Ren et al. [38] predicted the long-term cumulative plastic deformation of subgrade under cyclic loads using grey model. Wang and Li [39] adopted grey model for pavement smoothness prediction. Grey model was also used for the predictions in environmental vulnerability assessment [40], natural disasters [41] and road traffic [42], and so forth. GM $(1,1)$ (Grey Model First-Order One Variable) is one of the most widely used grey models in practical application [43]. However, the limitation existing in traditional GM $(1,1)$ is that it needs equal interval for time series data. It cannot be used for time series data with nonequal interval [44].

As discussed above, reuse of CR and diatomite possesses favorable economic and environmental benefits. Furthermore, F-T action has significant effect on the properties of asphalt pavement in seasonal frozen regions. It will reduce the pavement life severely. The compound modified effects of $\mathrm{CR}$ and diatomite, CR, and SBS on asphalt mixture under F$\mathrm{T}$ actions are still unknown. In order to improve the freezing resistance of asphalt pavement, crumb rubber modified stone mastic asphalt (CRSMA), crumb rubber and diatomite modified stone mastic asphalt (CRDSMA) and crumb rubber and SBS modified stone mastic asphalt (CRSSMA) were prepared, respectively. Effects of F-T cycles on three different kinds of asphalt mixtures were tested and evaluated using air voids, indirect tensile strength (ITS) test, and indirect tensile stiffness modulus (ITSM) test. Meanwhile, prediction analysis was used to construct the relationships between properties and F-T cycles in order to improve the convenience for performance analysis of mixture. Modified grey model MGM $(1,2)$ was applied for prediction of air void and ITS.

\section{Materials}

2.1. Raw Materials. Base asphalt AH-90 and SBS modified asphalt used for experiments were from Panjin Petrochemical Industry, Liaoning Province of China. Physical properties of AH-90 asphalt were measured and listed in Table 1. Properties of SBS modified asphalt were tested and given in Table 2. Aggregate and mineral filler were obtained from Changchun Municipal Mixing Plant in Jilin Province of China. Physical properties of andesite mineral aggregate were given in Table 3. Limestone powder was chosen as mineral filler. Corresponding properties of filler were listed in Table 4. Crumb rubber particle was obtained from Changchun Yuxing Rubber Materials Co., Ltd., Jilin Province, China. Its properties were shown in Table 5. Diatomite was produced by Changchun Diatomite Products Co., Ltd., Jilin Province, China. Its physical properties and particle distribution were listed in Tables 6 and 7. 
TABLE 1: Properties of neat asphalt.

\begin{tabular}{lcc}
\hline Property & Value & Technical criterion $(\%)$ \\
\hline Penetration $\left(25^{\circ} \mathrm{C}, 0.1 \mathrm{~mm}\right)$ & 84 & $80 \sim 100$ \\
Penetration index PI & -1.01 & $-1.5 \sim+1.0$ \\
Softening point TR\&B $\left({ }^{\circ} \mathrm{C}\right)$ & 44 & $\geq 42$ \\
Ductility $\left(15^{\circ} \mathrm{C}, \mathrm{cm}\right)$ & 150 & $\geq 100$ \\
Specific gravity $\left(15^{\circ} \mathrm{C}, \mathrm{g} / \mathrm{cm}^{3}\right)$ & 1.05 & - \\
After TFOT & & \\
Mass loss $(\%)$ & -0.3 & $\leq \pm 0.8$ \\
Penetration ratio $\left(25^{\circ} \mathrm{C}, \%\right)$ & 64 & $\geq 57$ \\
Age ductility $\left(10^{\circ} \mathrm{C}, \mathrm{cm}\right)$ & 14 & $\geq 8$ \\
\hline
\end{tabular}

TABLE 2: Properties of SBS modified asphalt.

\begin{tabular}{lcccc}
\hline Property & $\begin{array}{c}\text { Penetration } \\
\left(25^{\circ} \mathrm{C}, 0.1 \mathrm{~mm}\right)\end{array}$ & $\begin{array}{c}\text { Softening } \\
\text { point TR\&B } \\
\left({ }^{\circ} \mathrm{C}\right)\end{array}$ & $\begin{array}{c}\text { Ductility } \\
\left(5^{\circ} \mathrm{C}, \mathrm{cm}\right)\end{array}$ & $\begin{array}{c}\text { Viscosity } \\
\left(60^{\circ} \mathrm{C}, \mathrm{Pa} \cdot \mathrm{s}\right)\end{array}$ \\
\hline Value & 50 & 71 & 40 & 86 \\
\hline
\end{tabular}

2.2. Asphalt Mixture. Stone mastic asphalt (SMA) was developed in Germany during the 1960s. It has been used as the premium pavement surfacing course for heavy-duty pavements, high-speed motorways, and highways in America, Europe, China, and several other countries due to its excellent rutting resistance, fatigue resistance, durability, and lower noise characteristics compared with dense graded asphalt [ 45 , 46]. In this research, SMA-13 gradation was designed based on the Course Aggregate Void Filling (CAVF) method [47]. The designed gradation was shown in Figure 1. According to previous research results, the diatomite content $15 \%$ by weight of asphalt and crumb rubber content $3 \%$ by weight of aggregate were adopted [15]. Optimum asphalt contents were determined by Marshall method. They are 6.3\%, 6.5\%, and 6.6\% for CRSMA, CRDSMA, and CRSSMA, respectively.

In order to make crumb rubber and diatomite disperse homogeneous in the mixture, the preparation process was optimized. The designed preparation process for CRSMA was shown in Figure 2. Similar to the process in Figure 2, CRDSMA would be produced if filler was replaced with filler and diatomite; CRSSMA was obtained if neat asphalt was replaced with SBS modified asphalt. Detailed steps were explained as follows.

Step 1. Crumb rubber and aggregate were heated for $4 \mathrm{~h}$ at $180^{\circ} \mathrm{C}$, respectively. They were blended together using mixing pot (BH-10, Beijing Zhonghangkegong Instrument Co., Ltd., China). The blending temperature is $165^{\circ} \mathrm{C}$, speed is $80 \mathrm{r} / \mathrm{min}$, and time is $90 \mathrm{~s}$. This step is identical for CRSMA, CRDSMA, and CRSSMA.

Step 2. Asphalt was heated to $165^{\circ} \mathrm{C}$ and added to the mixture of crumb rubber and aggregate. They were blended together at $165^{\circ} \mathrm{C}$ for $90 \mathrm{~s}$ using mixing pot. The mixing speed is also set to be $80 \mathrm{r} / \mathrm{min}$. In this step, neat asphalt was used for CRSMA and CRDSMA, while it was SBS modified asphalt for CRSSMA.

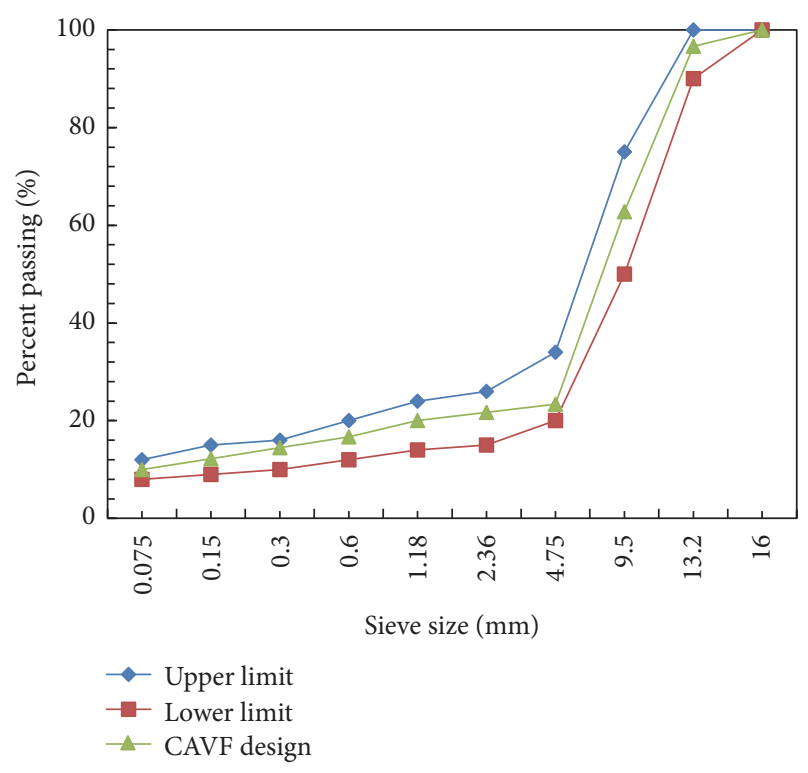

Figure 1: CAVF design gradation for SMA-13.

Step 3. Filler was heated for $4 \mathrm{~h}$ at $180^{\circ} \mathrm{C}$ and added to the mixture consisting of crumb rubber, aggregate, and asphalt (neat one for CRSMA and CRDSMA and SBS modified one for CRSSMA). They were blended together at the speed of $80 \mathrm{r} / \mathrm{min}$ and $165^{\circ} \mathrm{C}$ for $90 \mathrm{~s}$ using mixing pot. In this step, mineral powder was used for CRSMA and CRSSMA, while mineral powder and diatomite were used for CRDSMA.

Then, CRSMA, CRDSMA, and CRSSMA were prepared for testing. Marshall samples $(101 \mathrm{~mm}$ diameter and $63.5 \mathrm{~mm}$ height) were prepared by Marshall hammer method. For each sample, its weight is $1200 \mathrm{~g}$. According to the determined mixture proportion, aggregate $984.29 \mathrm{~g}$, mineral powder $109.37 \mathrm{~g}$, crumb rubber $32.81 \mathrm{~g}$, and neat asphalt $73.53 \mathrm{~g}$ were used for preparation of each CRSMA sample, while aggregate $973.02 \mathrm{~g}$, mineral powder $108.11 \mathrm{~g}$, crumb rubber $32.43 \mathrm{~g}$, neat asphalt $75.16 \mathrm{~g}$, and diatomite $11.28 \mathrm{~g}$ were used for each CRDSMA sample and aggregate $981.23 \mathrm{~g}$, mineral powder $109.02 \mathrm{~g}$, crumb rubber $32.71 \mathrm{~g}$, and SBS modified asphalt $77.04 \mathrm{~g}$ were used for each CRSSMA sample. The height of each sample was controlled to be $(63.5 \pm 1.3) \mathrm{mm}$.

\section{Experimental and Analytical Methods}

3.1. Process of Freeze-Thaw. In this research, the detailed processes of freeze-thaw were designed and listed as follows:

(1) The samples were divided into several groups. Each group consisted of three samples. One group of samples was placed at room temperature. Other groups of samples were immersed into water and placed in vacuum drying box for $15 \mathrm{~min}$ under vacuum degree $98.0 \mathrm{kPa}$. Then, vacuum drying box was adjusted to atmospheric condition. The samples were immersed into water for another $0.5 \mathrm{~h}$.

(2) Each sample was taken out of the tank and placed into plastic bag with $10 \mathrm{ml}$ water. The bag was put in 
TABLE 3: Properties of aggregate.

\begin{tabular}{|c|c|c|c|c|c|c|c|c|c|}
\hline Sieve size $(\mathrm{mm})$ & 13.2 & 9.5 & 4.75 & 2.36 & 1.18 & 0.6 & 0.3 & 0.15 & 0.075 \\
\hline Apparent density $\left(\mathrm{g} / \mathrm{cm}^{3}\right)$ & 2.811 & 2.796 & 2.786 & 2.710 & 2.678 & 2.675 & 2.628 & 2.627 & 2.618 \\
\hline Absorption coefficient of water (\%) & 0.89 & 1.01 & 1.43 & - & - & - & - & - & - \\
\hline
\end{tabular}

TABLE 4: Physical properties of mineral powder.

\begin{tabular}{|c|c|c|c|c|}
\hline \multirow{2}{*}{ Property } & \multirow{2}{*}{ Hydrophilic coefficient } & \multirow{2}{*}{ Apparent density $\left(\mathrm{g} / \mathrm{cm}^{3}\right)$} & \multicolumn{2}{|c|}{ Gradation } \\
\hline & & & Sieve size $(\mathrm{mm})$ & Passing (\%) \\
\hline \multirow{3}{*}{ Value } & & & 0.6 & 100 \\
\hline & 0.86 & 2.720 & 0.15 & 96.6 \\
\hline & & & 0.075 & 80.9 \\
\hline
\end{tabular}

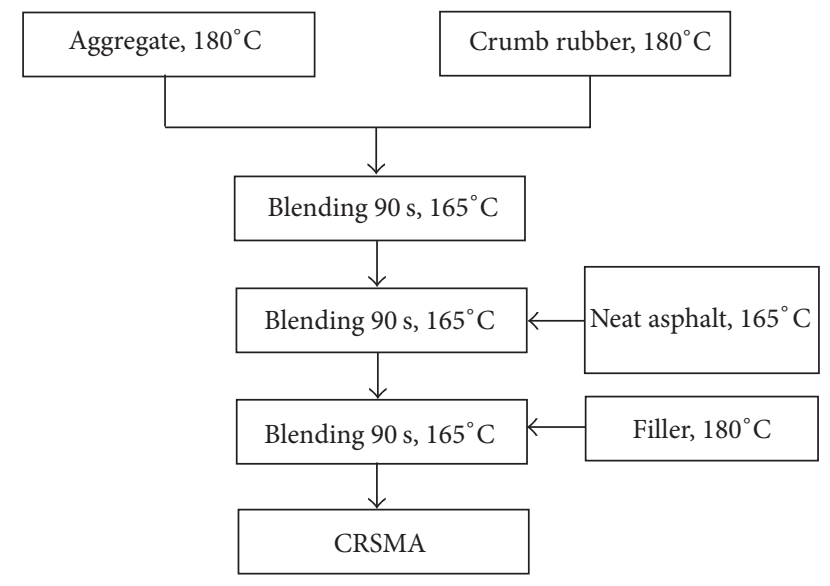

FIGURE 2: Designed preparation process for CRSMA.

refrigerator for $16 \mathrm{~h}$ at $-20^{\circ} \mathrm{C}$ until all the water in plastic bag was frozen.

(3) The samples were removed from plastic bags and placed into water tank for $8 \mathrm{~h}$ with constant temperature $60^{\circ} \mathrm{C}$ until all the water was melted.

After (1), (2), and (3), one F-T cycle was completed. In this study, the number of F-T cycles was 15 for ITS test and 10 for air void and ITSM tests. After F-T cycles, the samples were removed from plastic bags and placed into water tank for $24 \mathrm{~h}$ with constant temperature $60^{\circ} \mathrm{C}$. Then, they were put into water tank for $2 \mathrm{~h}$ with constant temperature $25^{\circ} \mathrm{C}$ and sample spacing was bigger than $10 \mathrm{~mm}$. The treated samples were used for air void, ITS, and ITSM tests.

3.2. Air Void Test. In this paper, air voids for samples were tested by surface-dry condition method according to standard AASHTO T-166 [48]. Firstly, Marshall specimens (101 mm diameter and $63.5 \mathrm{~mm}$ height) were prepared through compaction method with 75 blows on each side of cylindrical samples. Secondly, masses for samples in dry, water, and surface-dry conditions were measured, respectively. Bulk specific gravity for samples can be calculated by

$$
\gamma_{f}=\frac{m_{a}}{\left(m_{f}-m_{w}\right)}
$$

where $m_{a}, m_{w}$, and $m_{f}$ are masses of sample in dry, water, and surface-dry conditions, respectively. Then, the theoretical maximum specific gravity $\left(\gamma_{t}\right)$ of samples was tested through vacuum sealing method. Finally, air voids of samples can be obtained by

$$
V V=\left(1-\frac{\gamma_{f}}{\gamma_{t}}\right) \times 100 .
$$

Change ratio of air void was calculated by

$$
\Delta V V_{i}=\frac{\left(V V_{i}-V V_{i-1}\right)}{V V_{i}} \times 100,
$$

where $V V_{i}$ is the air void of mixture after $i$ times of F-T cycles, $i=1,2, \ldots, 10$.

3.3. Indirect Tensile Strength (ITS) Test. ITS test is an effective measure to evaluate the anticracking ability of asphalt mixture under low temperature $[4,21]$. In this research, the test was carried out according to standard AASHTO T-283 at temperature of $-10^{\circ} \mathrm{C}$ [48]. It is performed using a material testing machine (MQS-2) produced by Nanjing Ningxi Instrument Co., Ltd., Jiangsu Province, China. Loading rate was $1 \mathrm{~mm} / \mathrm{min}$. Marshall specimens $(101 \mathrm{~mm}$ diameter and $63.5 \mathrm{~mm}$ height) were placed in the chamber at $-10^{\circ} \mathrm{C}$ for $6 \mathrm{~h}$ before tests. The failure loads were recorded at the end of tests. ITS can be calculated by

$$
\mathrm{ITS}=\frac{(2 P)}{(\pi D t)},
$$

where ITS is the tensile strength of specimen; $P$ is the failure load; $D$ is the diameter of specimen; $t$ is the height of specimen.

In order to evaluate the F-T resistance ability of CRSMA, CRDSMA, and CRSSMA, change ratio of ITS before and after F-T cycles is given by

$$
\Delta \mathrm{ITS}_{i}=\frac{\left(\mathrm{ITS}^{B}-\mathrm{ITS}_{i}^{A}\right)}{\mathrm{ITS}^{B}} \times 100,
$$

where $\Delta \mathrm{ITS}_{i}$ is the change ratio of ITS after $i$ times of F-T cycles. ITS ${ }^{B}$ is ITS without F-T cycles, and $\operatorname{ITS}_{i}^{A}$ is ITS after $i$ times of F-T cycles. 
TABLE 5: Properties of crumb rubber particle.

\begin{tabular}{|c|c|c|c|c|c|}
\hline \multirow[b]{2}{*}{ Property } & \multirow[b]{2}{*}{$\begin{array}{c}\text { Sauer A hardness } \\
\left(^{\circ}\right)\end{array}$} & \multirow[b]{2}{*}{$\begin{array}{l}\text { Apparent density } \\
\qquad\left(\mathrm{g} / \mathrm{cm}^{3}\right)\end{array}$} & \multirow[b]{2}{*}{$\begin{array}{c}\text { Moisture content } \\
(\%)\end{array}$} & \multicolumn{2}{|c|}{ Gradation } \\
\hline & & & & $\begin{array}{l}\text { Sieve size } \\
(\mathrm{mm})\end{array}$ & $\begin{array}{c}\text { Passing } \\
(\%)\end{array}$ \\
\hline \multirow{3}{*}{ Value } & & & & 4.75 & 0.6 \\
\hline & 60 & 1.321 & 0.5 & 2.36 & 98.6 \\
\hline & & & & 1.18 & 0.8 \\
\hline
\end{tabular}

TABLE 6: Properties of diatomite.

Property Color PH Specific gravity $\left(\mathrm{g} / \mathrm{cm}^{3}\right)$ Bulk density $\left(\mathrm{g} / \mathrm{cm}^{3}\right)$ Loss on ignition (\%) Content of $\mathrm{SiO}_{2}(\%) \mathrm{Content}$ of $\mathrm{Fe} \mathrm{O}_{2}(\%)$

$\begin{array}{lllllll}\text { Value } & \text { Orange } & 8 \sim 10 & 2.152 & 0.37 & \leq 0.25 & \geq 87.1\end{array}$

3.4. Indirect Tensile Stiffness Modulus (ITSM) Test. In order to investigate the bearing capacity of asphalt mixture, ITSM test was performed according to standard AASHTO TP-31 [48]. ITSM test was widely used to analyze the tensile properties of mixture, which can be further related to the cracking performance of pavement. In this research, a multifunctional testing machine (NU-14) was used, which was produced by Cooper Research Technology, Ltd., United Kingdom. In order to investigate the antifreezing performance of modified asphalt mixtures, the tests were conducted at $5^{\circ} \mathrm{C}$ and Marshall specimens ( $101 \mathrm{~mm}$ diameter and $63.5 \mathrm{~mm}$ height) were adopted. The specimens were placed in the chamber at the test temperature for $6 \mathrm{~h}$ before tests. The schematic diagram [4] for load pulse was shown in Figure 3. Rise time was $124 \mathrm{~ms}$ and duration period was $3.0 \mathrm{~s}$. The target deformation in horizontal direction was $5 \mu \mathrm{m}$. The peak load was adjusted according to the test value of target deformation during the test. The stiffness modulus can be obtained by

$$
S_{m}=\frac{F \cdot(\mu+0.27)}{h \cdot Z}
$$

where $S_{m}$ is the stiffness modulus, $\mathrm{MPa} ; F$ is the peak load, $\mathrm{N} ; \mu$ is Poisson ratio, which is 0.25 at $5^{\circ} \mathrm{C} ; h$ is the height of specimen, $\mathrm{mm} ; Z$ is the measured deformation in horizontal direction, $\mathrm{mm}$.

Change ratio of $S_{m}$ before and after F-T cycles was calculated by

$$
\Delta S_{m i}=\frac{\left(S_{m}^{B}-S_{m i}^{A}\right)}{S_{m}^{B}} \times 100,
$$

where $\Delta S_{m i}$ is the change ratio of stiffness modulus after $i$ times of F-T cycles, $S_{m}^{B}$ is stiffness modulus without F-T cycles, and $S_{m i}^{A}$ is stiffness modulus after $i$ times of F-T cycles.

3.5. Modified Grey Method MGM $(1, m)$. Traditional GM $(1,1)$ can realize prediction of time series data with equal interval. It cannot be used for time series data with nonequal interval. In this research, time series data is the number of F-T cycles, which is $0,1,3,6,10$, and 15 with nonequal intervals. Therefore, the modified grey model (MGM) is used to construct the prediction model of air void and $\triangle$ ITS. The prediction procedure using MGM $(1, m)$ (Modified Grey

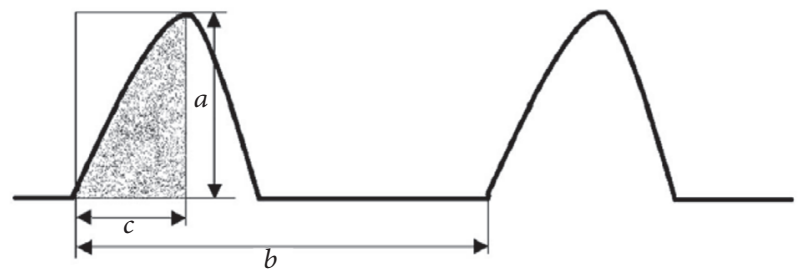

FIGURE 3: Load pulses in ITSM test: $a$ : peak load; $b$ : duration time; $c$ : rise time.

Model First-Order m Variables) is briefly introduced in this paper and listed in Appendix.

\section{Results and Discussion}

4.1. Air Voids. Air void is an important characteristic of internal structure that affects the moisture damage of asphalt mixture. Air voids of CRSMA, CRDSMA, and CRSSMA under $0,1,2, \ldots, 10$ times of F-T cycles were tested, respectively. Corresponding $\Delta V V_{i}(i=1,2, \ldots, 10)$ were calculated. Three specimens were measured for each case. For these measurements, mean value and standard deviation (SD) were calculated, respectively. Corresponding estimation of vertical error bar was determined for each case, which represents the standard deviation. Results of air voids (Mean \pm SD) and $\triangle V V$ for CRSMA, CRDSMA, and CRSSMA before and after F-T cycles are shown in Figures 4 and 5.

As can be seen from Figure 4, there is no significant increase or decrease in air void amplitude for each case. Air voids of CRSMA, CRDSMA, and CRSSMA are all below $7 \%$ after 10 times of F-T actions. Air voids increase with the increasing of F-T cycles, which agrees with the result obtained by Xu et al. [49]. Air void of CRSMA increases from $4.26 \%$ to $6.71 \%$ after 10 times of F-T cycles compared with that without F-T effect. It increases from $4.08 \%$ to $6.35 \%$ for CRDSMA and $4.09 \%$ to $6.01 \%$ for CRSSMA. The reasons lie in that F-T cycles can lead to not only expansion of existing voids but also formation of new voids [49]. Furthermore, air voids of CRSMA are generally larger than CRDSMA or CRSSMA, while air voids of CRSSMA are the lowest. According to the result by Song et al. [20], diatomite has 
TABLe 7: Particle distribution of diatomite.

\begin{tabular}{lccccc}
\hline Particle size $(\mu \mathrm{m})$ & $<5$ & $10 \sim 5$ & $20 \sim 10$ & $40 \sim 20$ & $>40$ \\
\hline Percentage $(\%)$ & 19.3 & 28.0 & 20.7 & 21.0 & 11.0 \\
\hline
\end{tabular}

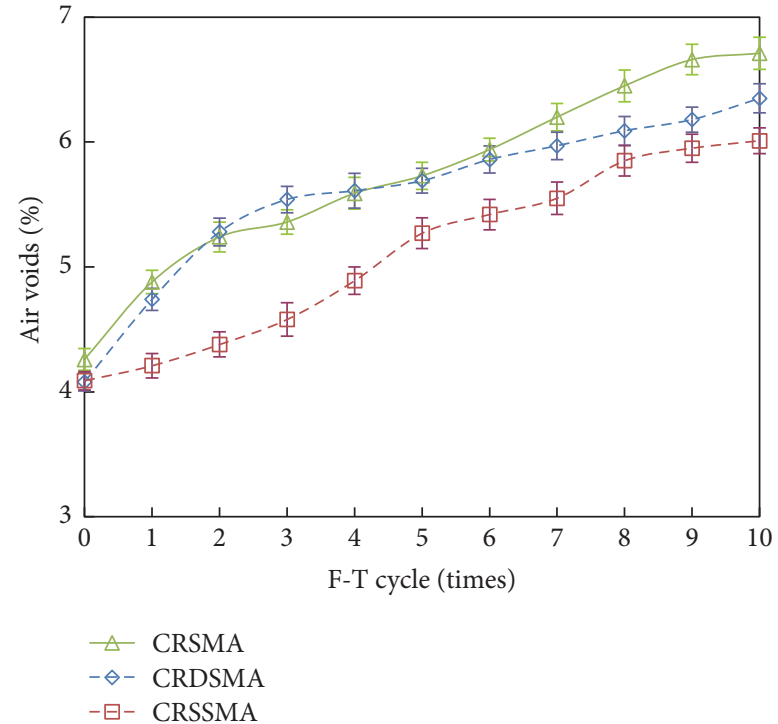

Figure 4: Air voids (Mean \pm SD) of CRSMA, CRDSMA, and CRSSMA before and after F-T cycles.

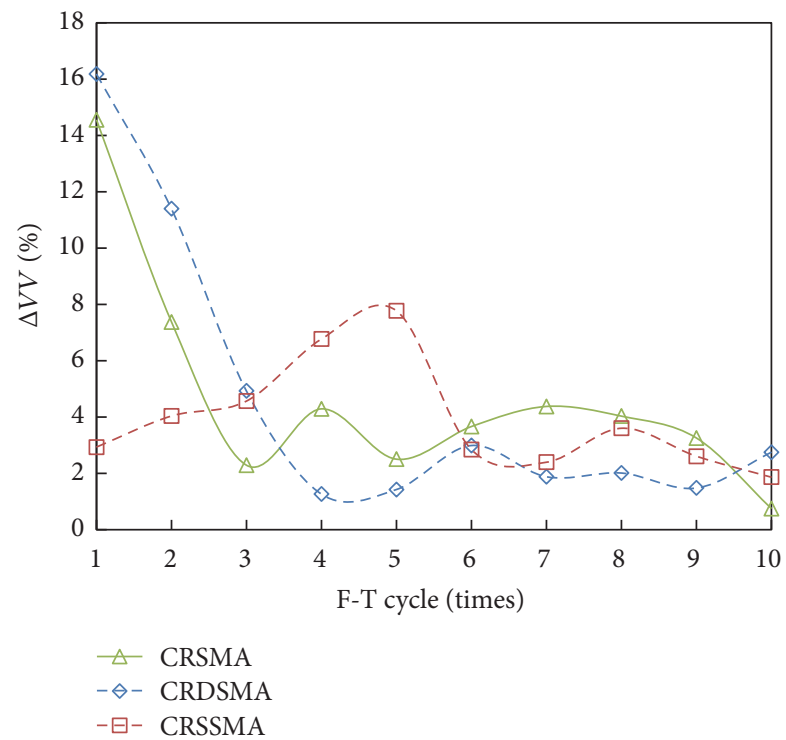

FIgURE 5: Change ratio of air void for CRSMA, CRDSMA, and CRSSMA.

larger void and absorption properties than mineral filler. It can effectively absorb the lower molecular group and lower polar aromatic molecules of asphalt to form thicker asphalt film and anchorage structure around aggregates and crumb rubber particles, which can increase the contact area and decrease the air voids between aggregates and rubber particles. According to the results of SBS modified asphalt by Larsen et al. [23] and Adedeji et al. [24], polymer phase and asphalt phase exist together. Polymer globules are dispersed homogenously in the continuous asphalt phase, which form a stable network structure. It can strengthen the adhesion between aggregate and rubber particle and decrease the air voids.

As shown in Figure 5, $\Delta V V_{1}$ are the largest for CRSMA and CRDSMA. It reveals that rapid expansion of existing voids and formation of new voids happen after the first F-T cycle. However, change ratio of air void for CRSSMA increases before 5 times of F-T cycles. It is induced by the strong network structure formed by two twisted continuous phases [22], which delays the growth of air void. Change ratios of air voids for CRSMA, CRDSMA, and CRSSMA tend to be stable after several times of F-T actions. It is because the expansion of existing voids and formation of new voids come to steady state.

The analysis of variance (ANOVA) is the most commonly used statistical method to determine the significant effects of factors [50]. ANOVA and F-T tests were conducted to determine statistically significant process parameters of F-T cycles on air voids for CRSMA, CRDSMA, and CRSSMA. ANOVA results were listed in Table 8.

According to ANOVA results, $F$ values of CRSMA, CRDSMA, and CRSSMA are all greater than $F_{0.01}$. The probability is $99 \%$ that F-T cycle possesses significant effects on air voids of CRSMA, CRDSMA, and CRSSMA. Besides, $F$ value of CRSMA is the largest, while $F$ value of CRSSMA is the smallest. The results indicate that F-T cycle presents the most statistically significant effect on air void of CRSMA and lowest one on CRSSMA. The additions of SBS and diatomite can reduce the influence of F-T cycles on air void.

4.2. ITS Results. ITS and $\triangle$ ITS were calculated for CRSMA, CRDSMA, and CRSSMA after F-T cycles $0,1,3,6,10$, and 15. Three specimens were measured for each case. For these measurements, mean value and standard deviation (SD) were calculated, respectively. Corresponding estimation of vertical error bar was determined for each case, which represents the standard deviation. Results of ITS (Mean \pm SD) and $\Delta$ ITS are shown in Figures 6 and 7.

As can be seen from Figures 6 and 7, ITS for three different kinds of asphalt mixtures all decrease with the increasing of F-T cycles and decrease rates become smaller. Meanwhile, $\triangle$ ITS of CRSMA, CRDSMA, and CRSSMA increase with the increasing of F-T cycles. The reasons lie in that repetitive F$\mathrm{T}$ actions increase the air voids, which is conducive to water flow. Effect of water frost will cause microcrack formation and propagation in asphalt mixture. These kinds of serious damage lead to the reduction of ITS. With the increasing of F-T cycles, air voids tend to be stable. Therefore, the frost effect of water slows down. Moreover, ITS of CRSSMA is the highest, while ITS of CRSMA is the lowest. Slowing trends for CRDSMA and CRSSMA are more obvious than CRSMA. With the increasing of F-T cycles, $\triangle$ ITS of CRSSMA is the 
TABLE 8: Analysis of variance (ANOVA) of F-T cycles on air void.

\begin{tabular}{|c|c|c|c|c|c|}
\hline Asphalt mixtures & Degree of freedom & $\begin{array}{c}\text { Sum of square for } \\
\text { deviance }\end{array}$ & $F$ value & $F_{0.01}$ & Significance \\
\hline CRSMA & & 17.695 & 143.264 & & $* *$ \\
\hline CRDSMA & 10 & 15.257 & 120.106 & 3.26 & $* *$ \\
\hline CRSSMA & & 13.589 & 118.599 & & $* *$ \\
\hline
\end{tabular}

${ }^{* *}$ Correlation is significant at the 0.01 level.

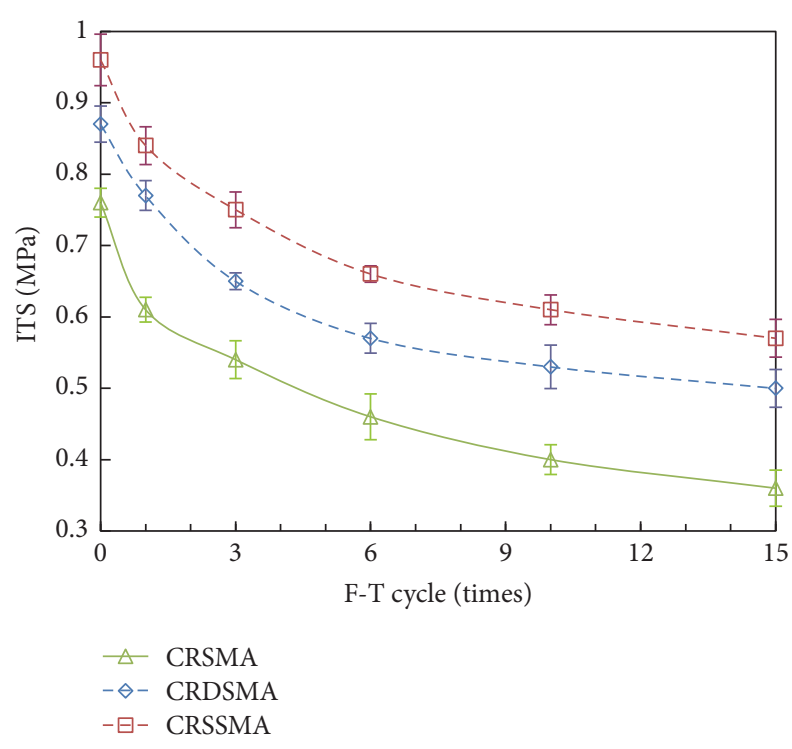

Figure 6: Relationship between ITS (Mean \pm SD) and F-T cycles.

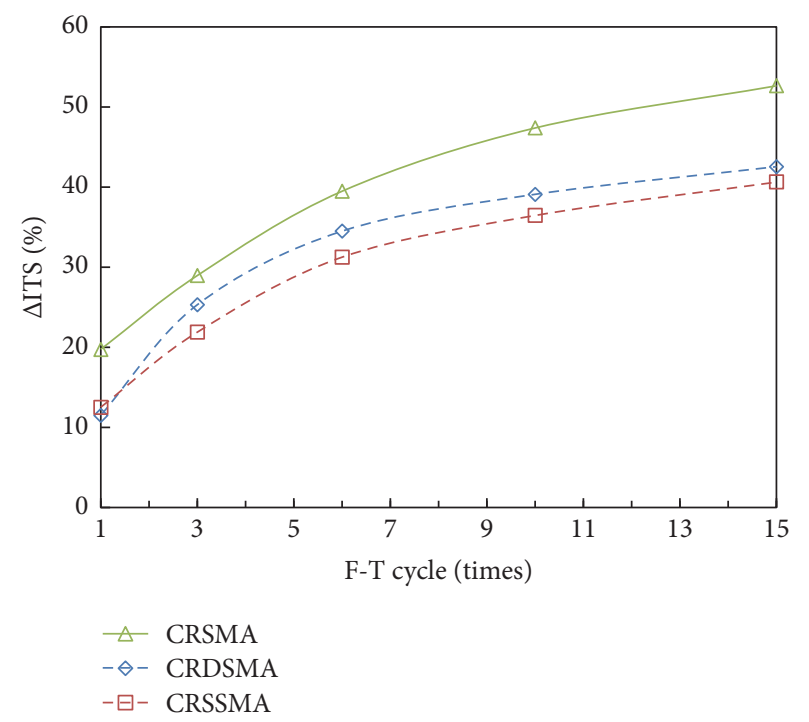

FIgURE 7: Relationship between $\Delta$ ITS and F-T cycles.

smallest, while it is the biggest for CRSMA. The reasons lie in that diatomite has good absorption ability of asphalt, which makes the adhesion capability of asphalt mortar increase and also the asphalt film thickness on aggregate surface $[20,35]$. Therefore, the cohesion among aggregates is strengthened and the anti-F-T ability of mixture improves, which enhances the resistance to internal damage of mixture. For SBS, its elastomeric phase can absorb the oil fraction of asphalt and swell it. A continuous polymer phase forms that can improve the performances of asphalt $[23,24]$. The network structure of SBS modified asphalt is more stable than diatomite modified one.

4.3. ITSM Results. $S_{m}$ of CRSMA, CRDSMA, and CRSSMA were tested and corresponding $\Delta S_{m}$ were calculated. Three specimens were measured for each case and the mean value was regarded as the result. Results for $S_{m}$ and $\Delta S_{m}$ are listed in Table 9.

As shown in Table 9, $S_{m}$ for CRSMA, CRDSMA, and CRSSMA decrease with the increasing of F-T cycles. $\Delta S_{m}$ increase with the increasing of F-T cycles. The reasons lie in that stiffness modulus is used to evaluate the bearing capacity of mixtures. Formation of microcrack under F-T action changes the internal structure and weakens its integrity of asphalt mixture [49], which reduces the bearing capacity. With the increasing of F-T cycles, the influence of internal damage is more obvious. Furthermore, CRSSMA possesses the highest stiffness modulus value, while CRSMA has the lowest one. It is because diatomite modified asphalt and SBS modified one have higher cohesion ability than the neat one [23], which can lower the degree of internal damage and also the bearing capacity for mixture. Similarly, network structure of SBS modified asphalt presents superior performance than diatomite modified one.

$S_{m}$ and ITS are important characteristics to represent the mechanical properties of asphalt mixture. Their correlations need to be demonstrated, which are shown in Figure 8. It can be observed that $S_{m}$ and ITS present favorable linear relationships. It can provide reference for the evaluation of mechanical properties of mixtures.

4.4. Performance Prediction. In practice, processes of F-T, air void, ITS, and ITSM tests are complicated and timeconsuming. They make the evaluation of mixture properties inconvenient. Prediction analysis can be used to construct the relationships between mixture properties and F-T cycles, which is convenient for performance analysis of mixture. In this paper, prediction models of air void and ITS for CRSMA, CRDSMA, and CRSSMA were established based on regression analysis and MGM $(1,2)$, respectively. The prediction effects of two models were compared and analyzed.

4.4.1. Regression Analysis Model. The regression analysis has been one of the most popular methods for performance 
TABLE 9: $S_{m}$ and $\Delta S_{m}$ for CRSMA, CRDSMA, and CRSSMA before and after F-T cycles.

\begin{tabular}{|c|c|c|c|c|c|}
\hline \multirow{3}{*}{ F-T cycles } & \multicolumn{5}{|c|}{ ITSM results } \\
\hline & \multicolumn{3}{|c|}{$S_{m}(\mathrm{MPa})$} & \multicolumn{2}{|c|}{$\Delta S_{m}(\mathrm{MPa})$} \\
\hline & 0 & 5 & 10 & 5 & 10 \\
\hline CRSMA & 6896 & 5080 & 4094 & 26.33 & 40.63 \\
\hline CRDSMA & 7532 & 5614 & 4930 & 25.48 & 34.56 \\
\hline CRSSMA & 7969 & 6332 & 5465 & 20.55 & 31.43 \\
\hline
\end{tabular}

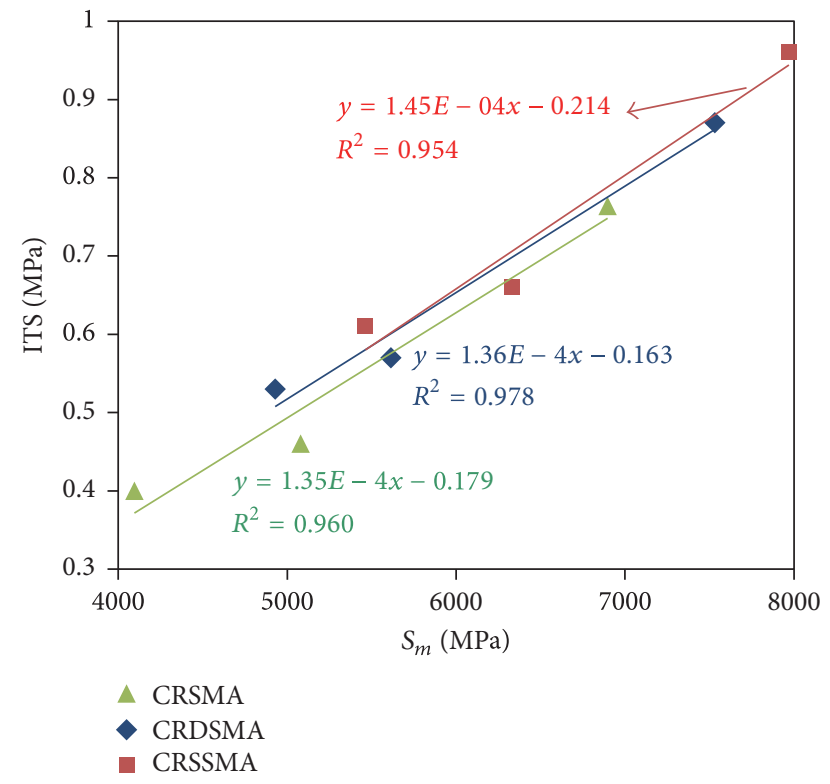

FIGURE 8: Relationship between $S_{m}$ and ITS.

prediction in many fields from decades [51-53]. Regression analysis consists of fitting a function to the data to discover how one or more variables (dependent variable) vary as a function of another (independent variable). In this study, independent variable is F-T cycles; dependent variables are air void and $\triangle \mathrm{ITS}$, respectively.

For CRSMA, $\triangle$ ITS is signed as variable $y_{C 1}$ and air void is $y_{C 2}$. For CRDSMA, $\triangle \mathrm{ITS}$ is signed as variable $y_{D 1}$ and air void is $y_{D 2}$. For CRSSMA, $\triangle$ ITS is signed as variable $y_{S 1}$ and air void is $y_{S 2}$. Regression models for CRSMA, CRDSMA, and CRSSMA are established based on the results of air voids and $\Delta$ ITS after $0,1,3,6$, and 10 times of F-T cycles. They are shown in Figures 9 and 10.

As can be seen from Figures 9 and 10, two order polynomials were used to construct the prediction models of $\triangle$ ITS for CRSMA, CRDSMA, and CRSSMA. $R^{2}$ values of the models for $\triangle I T S$ were higher than 0.97. Linear regression models were adopted for the prediction of air void for CRSMA and CRSSMA, and two order polynomials were used to for CRDSMA. $R^{2}$ values of the models for air void were higher than 0.95 . All these models revealed close agreements between experimental results and predicted ones.

The prediction results of $\Delta \mathrm{ITS}\left(\bar{y}_{C 1}, \bar{y}_{D 1}, \bar{y}_{S 1}\right)$ and air void $\left(\bar{y}_{C 2}, \bar{y}_{D 2}, \bar{y}_{S 2}\right)$ are calculated by use of the established regression models. The relative errors are obtained for $\triangle$ ITS

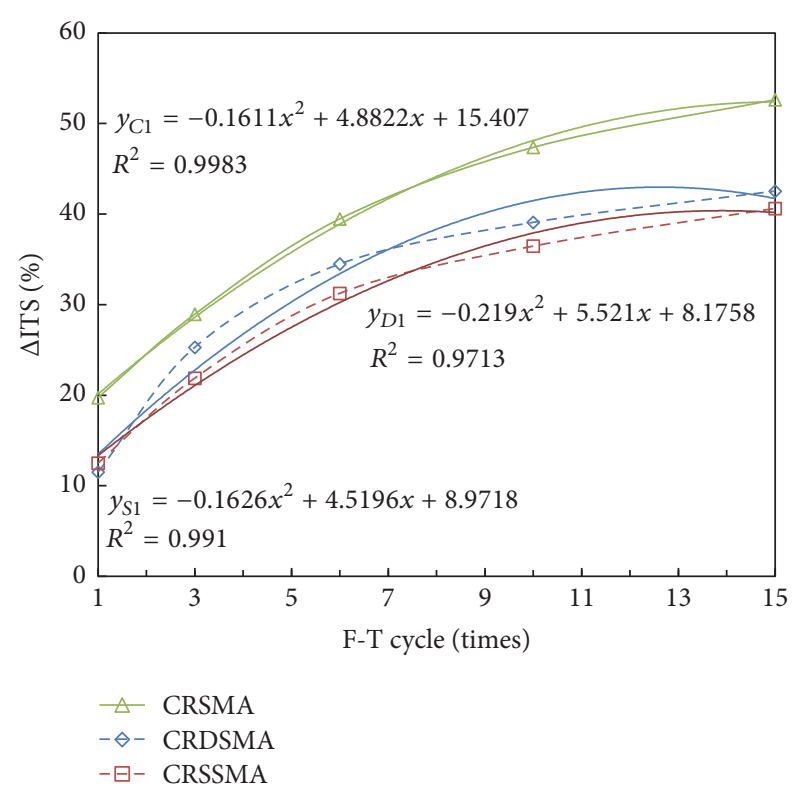

FIGURE 9: Regression models of $\triangle I T S$ for CRSMA, CRDSMA, and CRSSMA.

and air void after 15 times of F-T cycles, which can be calculated by

$$
\eta_{i}=\left|\frac{\left(\overline{y_{i}}-y_{i}\right)}{y_{i}} \times 100\right|,
$$

where $\eta$ is relative error between test value and predicted one; $y_{i}$ and $\overline{y_{i}}$ are test value and predicted one after $i$ th F-T cycles, respectively.

Corresponding root-mean-square error (RMSE) is also calculated, which is a frequently used measure of the differences between values predicted by a model and the values actually tested. The smaller RMSE is, the higher the prediction accuracy of model presents. RMSE can be calculated by

$$
\mathrm{RMSE}=\sqrt{\frac{\sum_{i=1}^{n}\left(\bar{y}_{i}-y_{i}\right)^{2}}{n}},
$$

where $n$ is the number of samples.

The prediction results of regression models are listed in Tables 10-12.

As shown in Tables 10,11, and 12, the relative errors for $\bar{y}_{\mathrm{C} 1}$ and $\bar{y}_{\mathrm{C} 2}$ after 15 times of F-T cycles are $1.15 \%$ and $3.09 \%$, respectively. They are $2.98 \%$ and $19.94 \%$ for $\bar{y}_{D 1}$ and $\bar{y}_{D 2}$ and $2.00 \%$ and $5.08 \%$ for $\bar{y}_{S 1}$ and $\bar{y}_{S 2}$. The prediction 
TABLE 10: Prediction results of $\bar{y}_{C 1}$ and $\bar{y}_{C 2}$ for CRSMA based on regression model.

\begin{tabular}{|c|c|c|c|c|c|c|c|c|}
\hline F-T cycle & $y_{C 1}$ & $\bar{y}_{C 1}$ & $\eta(\%)$ & RMSE (\%) & $y_{C 2}$ & $\bar{y}_{\mathrm{C} 2}$ & $\eta(\%)$ & RMSE (\%) \\
\hline 0 & 0 & 15.41 & - & \multirow{10}{*}{0.78} & 4.26 & 4.59 & 7.75 & \multirow{10}{*}{0.18} \\
\hline 1 & 20 & 20.13 & 0.65 & & 4.88 & 4.82 & 1.23 & \\
\hline 3 & 29 & 28.60 & 1.38 & & 5.36 & 5.27 & 1.68 & \\
\hline 6 & 40 & 38.90 & 2.75 & & 5.94 & 5.96 & 0.34 & \\
\hline 10 & 47 & 48.12 & 2.38 & & 6.71 & 6.87 & 2.38 & \\
\hline 11 & - & 49.62 & - & & - & 7.09 & - & \\
\hline 12 & - & 50.80 & - & & - & 7.32 & - & \\
\hline 13 & - & 51.65 & - & & - & 7.55 & - & \\
\hline 14 & - & 52.18 & - & & - & 7.78 & - & \\
\hline 15 & 53 & 52.39 & 1.15 & & 7.76 & 8.00 & 3.09 & \\
\hline
\end{tabular}

TABLE 11: Prediction results of $\bar{y}_{D 1}$ and $\bar{y}_{D 2}$ for CRDSMA based on regression model.

\begin{tabular}{|c|c|c|c|c|c|c|c|c|}
\hline F-T cycle & $y_{D 1}$ & $\bar{y}_{D 1}$ & $\eta(\%)$ & RMSE (\%) & $y_{D 2}$ & $\bar{y}_{D 2}$ & $\eta(\%)$ & RMSE (\%) \\
\hline 0 & 0 & 8.18 & - & \multirow{10}{*}{1.96} & 4.08 & 4.32 & 5.88 & \multirow{10}{*}{0.58} \\
\hline 1 & 11 & 13.48 & 22.55 & & 4.74 & 4.70 & 0.84 & \\
\hline 3 & 25 & 22.77 & 8.92 & & 5.54 & 5.34 & 3.61 & \\
\hline 6 & 34 & 33.42 & 1.71 & & 5.86 & 5.96 & 1.71 & \\
\hline 10 & 39 & 41.49 & 6.38 & & 6.35 & 6.19 & 2.52 & \\
\hline 11 & - & 42.41 & - & & - & 6.14 & - & \\
\hline 12 & - & 42.89 & - & & - & 6.05 & - & \\
\hline 13 & - & 42.94 & - & & - & 5.91 & - & \\
\hline 14 & - & 42.55 & - & & - & 5.73 & - & \\
\hline 15 & 43 & 41.72 & 2.98 & & 6.87 & 5.50 & 19.94 & \\
\hline
\end{tabular}

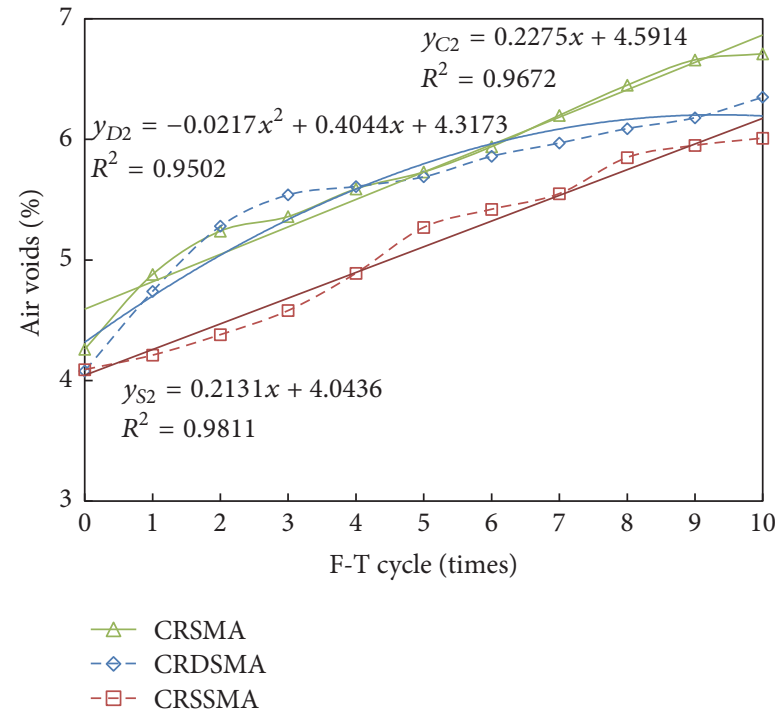

FIgURE 10: Regression models of air void for CRSMA, CRDSMA, and CRSSMA.

accuracy of $\bar{y}_{D 2}$ is close to $20 \%$, which is unsatisfactory. As for the maximum relative error, they are $2.75 \%, 7.75 \%, 22.55 \%$, $19.94 \%, 11.08 \%$, and $5.08 \%$ for $\bar{y}_{C 1}, \bar{y}_{C 2}, \bar{y}_{D 1}, \bar{y}_{D 2}, \bar{y}_{S 1}$, and $\bar{y}_{S 2}$, respectively. They are more than $5 \%$ except $\bar{y}_{C 1}$. In the aspect of RMSE, they are $0.78 \%, 0.18 \%, 1.96 \%, 0.58 \%, 1.23 \%$, and $0.17 \%$ for $\bar{y}_{C 1}, \bar{y}_{C 2}, \bar{y}_{D 1}, \bar{y}_{D 2}, \bar{y}_{S 1}$, and $\bar{y}_{S 2}$, respectively.
4.4.2. $\operatorname{MGM}(1,2)$ Model. For CRSMA, $\triangle \mathrm{ITS}$ is signed as variable $X_{C 1}^{(0)}$ and air void is $X_{C 2}^{(0)}$. MGM $(1,2)$ models for CRSMA are established based on the results of air voids and $\triangle$ ITS after $0,1,3,6$, and 10 times of F-T cycles.

For MGM $(1,2)$ models of CRSMA, the first-order differential equation is

$$
\begin{aligned}
& \frac{d X_{C 1}^{(1)}}{d t}=-0.4925 x_{C 1}^{(1)}+3.7466 x_{C 2}^{(1)}-0.4624, \\
& \frac{d X_{C 2}^{(1)}}{d t}=-0.0133 x_{C 1}^{(1)}+0.1254 x_{C 2}^{(1)}+4.1781 .
\end{aligned}
$$

Time response functions for $\Delta$ ITS and air void after 15 times of F-T cycles can be obtained as

$$
\begin{aligned}
\widehat{X}_{C}^{(1)}(15)= & e^{\left[\begin{array}{ll}
-0.4925 & 3.7466 \\
-0.0133 & 0.1254
\end{array}\right](15-0)}\left(\left[\begin{array}{c}
0 \\
4.26
\end{array}\right]+\left[\begin{array}{c}
1317 \\
173
\end{array}\right]\right) \\
& -\left[\begin{array}{c}
1317 \\
173
\end{array}\right] .
\end{aligned}
$$

The restored values for $\Delta \mathrm{ITS}$ and air void after 15 times of F-T cycles can be calculated by

$$
\widehat{X}_{C}^{(0)}(15)=\frac{\widehat{X}_{C}^{(1)}(15)-\widehat{X}_{C}^{(1)}(10)}{15-10}=\left[\begin{array}{c}
54.9960 \\
7.6912
\end{array}\right] .
$$


TABLE 12: Prediction results of $\bar{y}_{S 1}$ and $\bar{y}_{S 2}$ for CRSSMA based on regression model.

\begin{tabular}{|c|c|c|c|c|c|c|c|c|}
\hline F-T cycle & $y_{S 1}$ & $\bar{y}_{S 1}$ & $\eta(\%)$ & RMSE (\%) & $y_{S 2}$ & $\bar{y}_{S 2}$ & $\eta(\%)$ & RMSE (\%) \\
\hline 0 & 0 & 8.97 & - & \multirow{10}{*}{1.23} & 4.09 & 4.04 & 1.22 & \multirow{10}{*}{0.17} \\
\hline 1 & 12 & 13.33 & 11.08 & & 4.21 & 4.26 & 1.19 & \\
\hline 3 & 22 & 21.07 & -4.23 & & 4.58 & 4.68 & 2.18 & \\
\hline 6 & 31 & 30.24 & -2.45 & & 5.42 & 5.32 & 1.85 & \\
\hline 10 & 36 & 37.91 & 5.31 & & 6.01 & 6.17 & 2.66 & \\
\hline 11 & - & 39.01 & - & & - & 6.39 & - & \\
\hline 12 & - & 39.79 & - & & - & 6.60 & - & \\
\hline 13 & - & 40.25 & - & & - & 6.81 & - & \\
\hline 14 & - & 40.38 & - & & - & 7.03 & - & \\
\hline 15 & 41 & 40.18 & 2.00 & & 6.89 & 7.24 & 5.08 & \\
\hline
\end{tabular}

TABLE 13: Prediction results of $X_{C 1}^{(0)}$ and $X_{C 2}^{(0)}$ for CRSMA based on MGM $(1,2)$.

\begin{tabular}{|c|c|c|c|c|c|c|c|c|}
\hline F-T cycle & $X_{\mathrm{Cl}}^{(0)}$ & $\widehat{X}_{C 1}^{(0)}$ & $\eta(\%)$ & RMSE (\%) & $X_{C 2}^{(0)}$ & $\widehat{X}_{C 2}^{(0)}$ & $\eta(\%)$ & RMSE (\%) \\
\hline 0 & 0 & 0.00 & 0.00 & \multirow{10}{*}{1.01} & 4.26 & 4.26 & 0.00 & \multirow{10}{*}{0.03} \\
\hline 1 & 20 & 19.98 & 0.10 & & 4.88 & 4.89 & 0.20 & \\
\hline 3 & 29 & 29.84 & 2.90 & & 5.36 & 5.35 & 0.19 & \\
\hline 6 & 40 & 39.39 & 1.53 & & 5.94 & 5.95 & 0.17 & \\
\hline 10 & 47 & 47.15 & 0.32 & & 6.71 & 6.69 & 0.30 & \\
\hline 11 & - & 51.57 & - & & - & 7.23 & - & \\
\hline 12 & - & 52.42 & - & & - & 7.34 & - & \\
\hline 13 & - & 53.27 & - & & - & 7.46 & - & \\
\hline 14 & - & 54.13 & - & & - & 7.57 & - & \\
\hline 15 & 53 & 55.00 & 3.77 & & 7.76 & 7.69 & 0.90 & \\
\hline
\end{tabular}

The prediction results of $\Delta$ ITS $\left(\widehat{X}_{C 1}^{(0)}\right)$ and air void $\left(\widehat{X}_{C 2}^{(0)}\right)$ are calculated by use of the established $\operatorname{MGM}(1,2)$ model. The relative errors and RMSE are calculated for $\triangle$ ITS and air void after 15 times of F-T cycles. The prediction results of MGM (1, 2) model are listed in Table 13.

Prediction models of air voids and $\triangle I T S$ for CRDSMA and CRSSMA are also established based on $\operatorname{MGM}(1,2)$ according to the calculation procedure of CRSMA. For CRDSMA, $\triangle$ ITS is signed as variable $X_{D 1}^{(0)}$ and air void is $X_{D 2}^{(0)}$. The prediction results of $\Delta$ ITS $\left(\widehat{X}_{D 1}^{(0)}\right)$ and air void $\left(\widehat{X}_{D 2}^{(0)}\right)$ are calculated by use of the established $\operatorname{MGM}(1,2)$ model. The relative errors and RMSE are calculated for $\triangle$ ITS and air void after 15 times of F-T cycles. The prediction results of MGM (1, 2) model are listed in Table 14.

For CRSSMA, $\triangle$ ITS is signed as variable $X_{S 1}^{(0)}$ and air void is $X_{S 2}^{(0)}$. The prediction results of $\Delta$ ITS $\left(\widehat{X}_{S 1}^{(0)}\right)$ and air void $\left(\widehat{X}_{S 2}^{(0)}\right)$ are calculated by use of the established MGM $(1,2)$ model. The relative errors and RMSE are calculated for $\triangle$ ITS and air void after 15 times of F-T cycles. The prediction results of MGM $(1,2)$ model are listed in Table 15.

As shown in Tables 13,14, and 15, the relative errors for $\widehat{X}_{C 1}^{(0)}$ and $\widehat{X}_{C 2}^{(0)}$ after 15 times of F-T cycles are $3.77 \%$ and $0.90 \%$, respectively. They are $4.26 \%$ and $3.35 \%$ for $\widehat{X}_{D 1}^{(0)}$ and $\widehat{X}_{D 2}^{(0)}$ and $2.10 \%$ and $1.74 \%$ for $\widehat{X}_{S 1}^{(0)}$ and $\widehat{X}_{S 2}^{(0)}$. It reveals that the established MGM $(1,2)$ models possess favorable accuracy in performance prediction of CRSMA, CRDSMA and CRSSMA. As for the maximum relative error, they are
3.77\%, 0.90\%, 5.64\%, 3.35\%, 3.82\%, and 2.84\% for $\widehat{X}_{C 1}^{(0)}, \widehat{X}_{C 2}^{(0)}$, $\widehat{X}_{D 1}^{(0)}, \widehat{X}_{D 2}^{(0)}, \widehat{X}_{S 1}^{(0)}$, and $\widehat{X}_{S 2}^{(0)}$, respectively. They are less than $5 \%$ except $\widehat{X}_{D 1}^{(0)}$. In the aspect of RMSE, they are $1.01 \%, 0.03 \%$, $0.91 \%, 0.11 \%, 0.61 \%$, and $0.09 \%$ for $\widehat{X}_{C 1}^{(0)}, \widehat{X}_{C 2}^{(0)}, \widehat{X}_{D 1}^{(0)}, \widehat{X}_{D 2}^{(0)}, \widehat{X}_{S 1}^{(0)}$, and $\widehat{X}_{S 2}^{(0)}$, respectively.

Compared with regression models, the relative errors of MGM $(1,2)$ models in prediction of air void and $\triangle$ ITS after 15 times of F-T cycles are more stable and reliable. The maximum relative errors and RMSE of MGM $(1,2)$ models are much lower than regression ones except for $\triangle$ ITS of CRSMA. The results indicate that the differences between values predicted by MGM $(1,2)$ model and the values actually tested are smaller than regression model. MGM $(1,2)$ model presents more favorable accuracy in performance prediction of CRSMA, CRDSMA, and CRSSMA.

\section{Conclusions}

Reuse of waste materials is conducive to the protection of natural resources and environment. In this paper, $\mathrm{CR}$ and diatomite were recycled to modify SMA. CR, diatomite, and SBS were used to prepare CRSMA, CRDSMA, and CRSSMA. $\mathrm{F}-\mathrm{T}$ effects on these mixtures were investigated. The following conclusions can be obtained:

(1) Air voids of CRSMA, CRDSMA, and CRSSMA all increase with the increasing of F-T cycles. The addition of diatomite into CRSMA can reduce its air void 
TABLE 14: Prediction results of $X_{D 1}^{(0)}$ and $X_{D 2}^{(0)}$ for CRDSMA based on MGM $(1,2)$.

\begin{tabular}{|c|c|c|c|c|c|c|c|c|}
\hline F-T cycle & $X_{D 1}^{(0)}$ & $\widehat{X}_{D 1}^{(0)}$ & $\eta(\%)$ & RMSE (\%) & $X_{D 2}^{(0)}$ & $\widehat{X}_{D 2}^{(0)}$ & $\eta(\%)$ & RMSE (\%) \\
\hline 0 & 0 & 0 & 0.00 & \multirow{10}{*}{0.91} & 4.08 & 4.08 & 0 & \multirow{10}{*}{0.11} \\
\hline 1 & 11 & 11.62 & 5.64 & & 4.74 & 4.80 & 1.27 & \\
\hline 3 & 25 & 24.98 & 0.08 & & 5.54 & 5.44 & 1.81 & \\
\hline 6 & 34 & 33.39 & 1.45 & & 5.86 & 5.96 & 1.71 & \\
\hline 10 & 39 & 38.72 & 0.72 & & 6.35 & 6.31 & 0.63 & \\
\hline 11 & - & 40.24 & - & & - & 6.50 & - & \\
\hline 12 & - & 40.42 & - & & - & 6.53 & - & \\
\hline 13 & - & 40.72 & - & & - & 6.57 & - & \\
\hline 14 & - & 40.94 & - & & - & 6.6 & - & \\
\hline 15 & 43 & 41.17 & 4.26 & & 6.87 & 6.64 & 3.35 & \\
\hline
\end{tabular}

TABLE 15: Prediction results of $X_{S 1}^{(0)}$ and $X_{S 2}^{(0)}$ for CRSSMA based on MGM $(1,2)$.

\begin{tabular}{|c|c|c|c|c|c|c|c|c|}
\hline F-T cycle & $X_{S 1}^{(0)}$ & $\widehat{X}_{S 1}^{(0)}$ & $\eta(\%)$ & RMSE (\%) & $X_{S 2}^{(0)}$ & $\widehat{X}_{S 2}^{(0)}$ & $\eta(\%)$ & RMSE (\%) \\
\hline 0 & 0 & 0 & 0.00 & \multirow{10}{*}{0.61} & 4.09 & 4.09 & 0.00 & \multirow{10}{*}{0.09} \\
\hline 1 & 12 & 12.2 & 1.67 & & 4.21 & 4.18 & 0.71 & \\
\hline 3 & 22 & 22.84 & 3.82 & & 4.58 & 4.71 & 2.84 & \\
\hline 6 & 31 & 30.43 & 1.84 & & 5.42 & 5.3 & 2.21 & \\
\hline 10 & 36 & 35.76 & 0.69 & & 6.01 & 6.02 & 0.17 & \\
\hline 11 & - & 39.06 & - & & - & 6.55 & - & \\
\hline 12 & - & 39.74 & - & & - & 6.66 & - & \\
\hline 13 & - & 40.43 & - & & - & 6.77 & - & \\
\hline 14 & - & 41.14 & - & & - & 6.89 & - & \\
\hline 15 & 41 & 41.86 & 2.10 & & 6.89 & 7.01 & 1.74 & \\
\hline
\end{tabular}

because diatomite can effectively absorb the lower molecular group and lower polar aromatic molecules of asphalt to form thicker asphalt film and anchorage structure around aggregates and crumb rubber particles. As for the effect of SBS, it can also reduce the air void of CRSMA because of the strong network structure of SBS modified asphalt. CRSSMA presents the lowest air voids during the test. ANOVA results reveal that F-T cycle presents the lowest statistically significant effect on air void of CRSSMA.

(2) Indirect tensile strength for three different kinds of asphalt mixtures all decrease with the increasing of F-T cycles. Diatomite and SBS present enhancement effects for indirect tensile strength of CRSMA. Anchorage structure of diatomite modified asphalt and continuous polymer phase of SBS modified asphalt can improve the cohesion among aggregates and enhances the resistance of mixture to internal damage. Results for change ratio of tensile strength before and after F-T cycles reveal that CRSSMA is the smallest and CRSMA is the biggest.

(3) Indirect tensile stiffness modulus of CRSMA, CRDSMA, and CRSSMA decreases with the increasing of F-T cycles. Diatomite and SBS can effectively improve the stiffness modulus of CRSMA, which is because diatomite modified asphalt and SBS modified one have higher cohesion abilities than the neat one.
CRSSMA possesses the highest stiffness modulus value. Stiffness modulus and indirect tensile strength present favorable linear relationship.

(4) The differences between values predicted by MGM (1, 2) model and the values actually tested are smaller than regression model. It indicates that MGM model presents more favorable accuracy and can be used for performance prediction of asphalt mixtures.

In summary, the network structure of SBS modified asphalt is more stable than diatomite modified one. Pavement constructed using CRSSMA will have the better antifreezing performance than that using CRSMA or CRDSMA. However, the pavement constructed using CRDSMA will be a favorable choice considering its environmental and economic advantages. It not only presents good antifreezing performance but also realizes the reuse of waste materials including CR and diatomite.

\section{Appendix}

\section{Modified Grey Method MGM $(1, m)$}

The prediction procedure using MGM $(1, m)$ (Modified Grey Model First-Order $m$ Variables) is briefly introduced as follows:

Step 1. Assume that the original series of data with $m$ variables are 


$$
\begin{aligned}
X^{(0)}= & {\left[\begin{array}{c}
X_{1}^{(0)} \\
X_{2}^{(0)} \\
\vdots \\
X_{m}^{(0)}
\end{array}\right] } \\
= & {\left[\begin{array}{cccc}
x_{1}^{(0)}\left(k_{1}\right) & x_{1}^{(0)}\left(k_{2}\right) & \cdots & x_{1}^{(0)}\left(k_{n}\right) \\
x_{2}^{(0)}\left(k_{1}\right) & x_{2}^{(0)}\left(k_{2}\right) & \cdots & x_{2}^{(0)}\left(k_{n}\right) \\
\vdots & \vdots & & \vdots \\
x_{m}^{(0)}\left(k_{1}\right) & x_{m}^{(0)}\left(k_{2}\right) & \cdots & x_{m}^{(0)}\left(k_{n}\right)
\end{array}\right], }
\end{aligned}
$$

where $X^{(0)}$ is the nonnegative original time series data; $m$ is the number of variables. $X_{j}^{(0)}(j=1,2, \ldots, m)$ is the $j$ th variable with nonequal interval; $n$ is the number of time series data for variables. $X_{j}^{(0)}\left(k_{i}\right)$ is the data at time $k_{i}$.

Step 2. One time accumulating generation operational sequences (1-AGO sequences) for $X_{1}^{(0)}, X_{2}^{(0)}, \ldots, X_{m}^{(0)}$ are

$$
\begin{aligned}
X^{(1)} & =\left[\begin{array}{c}
X_{1}^{(1)} \\
X_{2}^{(1)} \\
\vdots \\
X_{m}^{(1)}
\end{array}\right] \\
= & {\left[\begin{array}{cccc}
x_{1}^{(1)}\left(k_{1}\right) & x_{1}^{(1)}\left(k_{2}\right) & \cdots & x_{1}^{(1)}\left(k_{n}\right) \\
x_{2}^{(1)}\left(k_{1}\right) & x_{2}^{(1)}\left(k_{2}\right) & \cdots & x_{2}^{(1)}\left(k_{n}\right) \\
\vdots & \vdots & & \vdots \\
x_{m}^{(1)}\left(k_{1}\right) & x_{m}^{(1)}\left(k_{2}\right) & \cdots & x_{m}^{(1)}\left(k_{n}\right)
\end{array}\right], }
\end{aligned}
$$

where $X_{j}^{(1)}$ is the AGO sequence of $X_{j}^{(0)} ; x_{j}^{(1)}\left(k_{i}\right)=$ $\sum_{l=1}^{i} x_{j}^{(0)}\left(k_{l}\right) \Delta k_{l}, \Delta k_{l}$ is the interval between $k_{l}$ and $k_{l-1}$.

Step 3. MGM $(1, m)$ model can be obtained by the following first-order differential equation:

$$
\begin{gathered}
\frac{d X_{1}^{(1)}}{d t}=a_{11} x_{1}^{(1)}+a_{12} x_{2}^{(1)}+\cdots+a_{1 m} x_{m}^{(1)}+b_{1}, \\
\frac{d X_{2}^{(1)}}{d t}=a_{21} x_{1}^{(1)}+a_{22} x_{2}^{(1)}+\cdots+a_{2 m} x_{m}^{(1)}+b_{2}, \\
\vdots \\
\frac{d X_{m}^{(1)}}{d t}=a_{m 1} x_{1}^{(1)}+a_{m 2} x_{2}^{(1)}+\cdots+a_{m m} x_{m}^{(1)}+b_{m} . \\
\text { Assume } A=\left[\begin{array}{cccc}
a_{11} & a_{12} & \ldots & a_{1 m} \\
a_{21} & a_{22} & \cdots & a_{2 m} \\
\vdots & \vdots & & \vdots \\
a_{m 1} & a_{m 2} & \cdots & a_{m m}
\end{array}\right], B=\left[\begin{array}{c}
b_{1} \\
b_{2} \\
\vdots \\
b_{m}
\end{array}\right] .
\end{gathered}
$$

Then, (A.3) can be expressed by

$$
\frac{d X^{(1)}}{d t}=A X^{(1)}+B,
$$

where $X^{(1)}=\left\{X_{1}^{(1)}, X_{2}^{(1)}, \ldots, X_{m}^{(1)}\right\}^{T}$.

Step 4. The solution of (A.4) is

$$
X^{(1)}\left(k_{i}\right)=e^{A\left(k_{i}-k_{1}\right)}\left(X^{(1)}\left(k_{1}\right)+A^{-1} B\right)-A^{-1} B
$$

which is called the time response function. In (A.5), matrix $A$ and vector $B$ are undetermined.

Step 5. Solution of $A$ and $B$. The generating sequence for nearest-neighbor mean value with nonequal interval is

$$
Z_{j}^{(1)}=\left\{z_{j}^{(1)}\left(k_{2}\right), z_{j}^{(1)}\left(k_{3}\right), \ldots, z_{j}^{(1)}\left(k_{n}\right)\right\},
$$

where $z_{j}^{(1)}\left(k_{i}\right)=0.5\left(x_{j}^{(1)}\left(k_{i-1}\right)+x_{j}^{(1)}\left(k_{i}\right)\right)$.

Difference equation for (A.5) can be obtained after discretization; it is

$$
x_{j}^{(0)}\left(k_{i}\right)=\sum_{l=1}^{m} a_{j l} z_{l}^{(1)}\left(k_{i}\right)+b_{j} .
$$

Least squares estimation sequence for $\operatorname{MGM}(1, m)$ is

$$
\widehat{a}_{j}=\left(\widehat{a}_{j 1}, \widehat{a}_{j 2}, \ldots, \widehat{a}_{j m}, \widehat{b}_{j}\right)^{T}=\left(P^{T} P\right)^{-1} P^{T} Y_{j},
$$

where

$$
\begin{aligned}
& P=\left[\begin{array}{cccccc}
z_{1}^{(1)}\left(k_{2}\right) & z_{2}^{(1)}\left(k_{2}\right) & \cdots & z_{m}^{(1)}\left(k_{2}\right) & 1 \\
z_{1}^{(1)}\left(k_{3}\right) & z_{2}^{(1)}\left(k_{3}\right) & \cdots & z_{m}^{(1)}\left(k_{3}\right) & 1 \\
\vdots & \vdots & & \vdots & \vdots \\
z_{1}^{(1)}\left(k_{n}\right) & z_{2}^{(1)}\left(k_{n}\right) & \cdots & z_{m}^{(1)}\left(k_{n}\right) & 1
\end{array}\right], \\
& Y_{j}=\left\{x_{j}^{(0)}\left(k_{2}\right), x_{j}^{(0)}\left(k_{3}\right), \ldots, x_{j}^{(0)}\left(k_{n}\right)\right\}^{T} \\
& (j=1,2, \ldots, m) .
\end{aligned}
$$

Matrix $A$ and vector $B$ can be calculated by

$$
\begin{aligned}
\widehat{A} & =\left(\widehat{a}_{i j}\right)_{m \times m} ; \\
\widehat{B} & =\left(\widehat{b}_{1}, \widehat{b}_{2}, \ldots, \widehat{b}_{m}\right)^{T} .
\end{aligned}
$$

Step 6. Time response function of difference equation $x_{j}^{(0)}\left(k_{i}\right)=\sum_{l=1}^{m} a_{j l} z_{l}^{(1)}\left(k_{i}\right)+b_{j}$ is

$$
\begin{aligned}
\widehat{X}^{(1)}\left(k_{i}\right) & =\left\{\widehat{x}_{1}^{(1)}\left(k_{i}\right), \widehat{x}_{2}^{(1)}\left(k_{i}\right), \ldots, \widehat{x}_{m}^{(1)}\left(k_{i}\right)\right\}^{T} \\
& =e^{\widehat{A}\left(k_{i}-k_{1}\right)}\left(X^{(1)}\left(k_{1}\right)+\widehat{A}^{-1} \widehat{B}\right)-\widehat{A}^{-1} \widehat{B} .
\end{aligned}
$$

Step 7. The restored values can be obtained as follows:

$$
\begin{aligned}
\widehat{X}^{(0)}\left(k_{i}\right) & =\left\{\widehat{x}_{1}^{(0)}\left(k_{i}\right), \widehat{x}_{2}^{(0)}\left(k_{i}\right), \ldots, \widehat{x}_{m}^{(0)}\left(k_{i}\right)\right\}^{T} \\
& =\frac{\widehat{X}^{(1)}\left(k_{i}\right)-\widehat{X}^{(1)}\left(k_{i-1}\right)}{\Delta k_{i}} .
\end{aligned}
$$




\section{Conflicts of Interest}

The authors declare no conflicts of interest.

\section{Acknowledgments}

The authors express their appreciations for the financial supports of National Natural Science Foundation of China under Grants nos. 51408258 and 51578263; China Postdoctoral Science Foundation Funded Project (nos. 2014M560237 and 2015T80305); Fundamental Research Funds for the Central Universities (JCKYQKJC06), Transportation Science and Technology Project of Jilin Province (2015-1-11), and Science $\&$ Technology Development Program of Jilin Province.

\section{References}

[1] L. D. Poulikakos, C. Papadaskalopoulou, B. Hofko et al., "Harvesting the unexplored potential of european waste materials for road construction," Resources, Conservation and Recycling, vol. 116, pp. 32-44, 2017.

[2] Y. Zhang, Q. Guo, L. Li, P. Jiang, Y. Jiao, and Y. Cheng, "Reuse of boron waste as an additive in road base material," Materials, vol. 9, no. 6, article 416, 2016.

[3] M. A. Mull, K. Stuart, and A. Yehia, "Fracture resistance characterization of chemically modified crumb rubber asphalt pavement," Journal of Materials Science, vol. 37, no. 3, pp. 557566, 2002.

[4] F. M. Navarro and M. C. R. Gámez, "Influence of crumb rubber on the indirect tensile strength and stiffness modulus of hot bituminous mixes," Journal of Materials in Civil Engineering, vol. 24, no. 6, pp. 715-724, 2012.

[5] A. I. B. Farouk, N. A. Hassan, M. Z. Mahmud et al., "Effects of mixture design variables on rubber-bitumen interaction: properties of dry mixed rubberized asphalt mixture," Materials and Structures, vol. 50, no. 1 article 12, 2017.

[6] M. F. Azizian, P. O. Nelson, P. Thayumanavan, and K. J. Williamson, "Environmental impact of highway construction and repair materials on surface and ground waters: case study. Crumb rubber asphalt concrete," Waste Management, vol. 23, no. 8, pp. 719-728, 2003.

[7] M. Bueno, J. Luong, F. Terán, U. Viñuela, and S. E. Paje, "Macrotexture influence on vibrational mechanisms of the tyreroad noise of an asphalt rubber pavement," International Journal of Pavement Engineering, vol. 15, no. 7, pp. 606-613, 2014.

[8] G. A. J. Mturi, J. O’Connell, S. E. Zoorob, and M. De Beer, "A study of crumb rubber modified bitumen used in South Africa," Road Materials and Pavement Design, vol. 15, no. 4, pp. 774-790, 2014.

[9] A. D. La Rosa, G. Recca, D. Carbone et al., "Environmental benefits of using ground tyre rubber in new pneumatic formulations: a life cycle assessment approach," Proceedings of the Institution of Mechanical Engineers, Part L: Journal of Materials: Design and Applications, vol. 229, no. 4, pp. 309-317, 2015.

[10] A. Farina, M. C. Zanetti, E. Santagata, and G. A. Blengini, "Life cycle assessment applied to bituminous mixtures containing recycled materials: crumb rubber and reclaimed asphalt pavement," Resources, Conservation and Recycling, vol. 117, pp. 204212, 2017.

[11] H. H. Kim and S.-J. Lee, "Evaluation of rubber influence on cracking resistance of crumb rubber modified binders with wax additives," Canadian Journal of Civil Engineering, vol. 43, no. 4, pp. 326-333, 2016.

[12] H. Ziari, A. Goli, and A. Amini, "Effect of crumb rubber modifier on the performance properties of rubberized binders," Journal of Materials in Civil Engineering, vol. 28, no. 12, Article ID 04016156, 2016.

[13] Z. Xie and J. Shen, "Performance of porous European mix (PEM) pavements added with crumb rubbers in dry process," International Journal of Pavement Engineering, vol. 17, no. 7, pp. 637-646, 2016.

[14] M. Liang, X. Xin, W. Fan, H. Sun, Y. Yao, and B. Xing, "Viscous properties, storage stability and their relationships with microstructure of tire scrap rubber modified asphalt," Construction and Building Materials, vol. 74, pp. 124-131, 2015.

[15] A. F. De Almeida Júnior, R. A. Battistelle, B. S. Bezerra, and R. De Castro, "Use of scrap tire rubber in place of SBS in modified asphalt as an environmentally correct alternative for Brazil," Journal of Cleaner Production, vol. 33, pp. 236-238, 2012.

[16] H. Wei, Q. He, Y. Jiao, J. Chen, and M. Hu, "Evaluation of antiicing performance for crumb rubber and diatomite compound modified asphalt mixture," Construction and Building Materials, vol. 107, pp. 109-116, 2016.

[17] N. A. Mohamed Abdullah, N. Abdul Hassan, N. A. Mohd Shukry et al., "Evaluating potential of diatomite as anti clogging agent for porous asphalt mixture," Jurnal Teknologi, vol. 78, no. 7-2, pp. 105-111, 2016.

[18] P. Cong, N. Liu, Y. Tian, and Y. Zhang, "Effects of long-term aging on the properties of asphalt binder containing diatoms," Construction and Building Materials, vol. 123, pp. 534-540, 2016.

[19] Y. Cheng, J. Tao, Y. Jiao, Q. Guo, and C. Li, "Influence of diatomite and mineral powder on thermal oxidative ageing properties of asphalt," Advances in Materials Science and Engineering, vol. 2015, Article ID 947834, 10 pages, 2015.

[20] Y. Song, J. Che, and Y. Zhang, "The interacting rule of diatomite and asphalt groups," Petroleum Science and Technology, vol. 29, no. 3, pp. 254-259, 2011.

[21] Y. Q. Tan, L. Zhang, and X. Y. Zhang, "Investigation of lowtemperature properties of diatomite-modified asphalt mixtures," Construction and Building Materials, vol. 36, pp. 787-795, 2012.

[22] Q. Guo, L. Li, Y. Cheng, Y. Jiao, and C. Xu, "Laboratory evaluation on performance of diatomite and glass fiber compound modified asphalt mixture," Materials \& Design, vol. 66, pp. 5159, 2015.

[23] D. O. Larsen, J. L. Alessandrini, A. Bosch, and M. S. Cortizo, "Micro-structural and rheological characteristics of SBSasphalt blends during their manufacturing," Construction and Building Materials, vol. 23, no. 8, pp. 2769-2774, 2009.

[24] A. Adedeji, T. Grünfelder, F. S. Bates, C. W. Macosko, M. Stroup-Gardiner, and D. E. Newcomb, "Asphalt modified by SBS triblock copolymer: structures and properties," Polymer Engineering and Science, vol. 36, no. 12, pp. 1707-1723, 1996.

[25] R. Blanco, R. Rodríguez, M. García-Garduño, and V. M. Castaño, "Rheological properties of styrene-butadiene copolymer-reinforced asphalt," Journal of Applied Polymer Science, vol. 61, no. 9, pp. 1493-1501.

[26] A. Khodaii and A. Mehrara, "Evaluation of permanent deformation of unmodified and SBS modified asphalt mixtures using dynamic creep test," Construction and Building Materials, vol. 23, no. 7, pp. 2586-2592, 2009. 
[27] D. Sun, F. Ye, F. Shi, and W. Lu, "Storage stability of SBSmodified road asphalt: preparation, morphology, and rheological properties," Petroleum Science and Technology, vol. 24, no. 9, pp. 1067-1077, 2006.

[28] S. Wen and D. D. L. Chung, "Double percolation in the electrical conduction in carbon fiber reinforced cement-based materials," Carbon, vol. 45, no. 2, pp. 263-267, 2007.

[29] S. S. Awanti, M. S. Amarnath, and A. Veeraragavan, "Laboratory evaluation of SBS modified bituminous paving mix," Journal of Materials in Civil Engineering, vol. 20, no. 4, pp. 327-330, 2008.

[30] F. Dong, X. Yu, S. Liu, and J. Wei, "Rheological behaviors and microstructure of SBS/CR composite modified hard asphalt," Construction and Building Materials, vol. 115, pp. 285-293, 2016.

[31] H. Liu, F. Niu, Y. Niu, Z. Lin, J. Lu, and J. Luo, "Experimental and numerical investigation on temperature characteristics of high-speed railway's embankment in seasonal frozen regions," Cold Regions Science and Technology, vol. 81, pp. 55-64, 2012.

[32] A. Richardson, K. Coventry, V. Edmondson, and E. Dias, "Crumb rubber used in concrete to provide freeze-thaw protection (optimal particle size)," Journal of Cleaner Production, vol. 112, pp. 599-606, 2016.

[33] L. Zhang, T.-S. Li, and Y.-Q. Tan, “The potential of using impact resonance test method evaluating the anti-freeze-thaw performance of asphalt mixture," Construction and Building Materials, vol. 115, pp. 54-61, 2016.

[34] J. L. Deng, “The control problems of grey systems," Systems \& Control Letters, vol. 1, no. 5, pp. 288-294, 1982.

[35] D.-H. Shen and J.-C. Du, "Application of gray relational analysis to evaluate HMA with reclaimed building materials," Journal of Materials in Civil Engineering, vol. 17, no. 4, pp. 400-406, 2005.

[36] P. Zhang, C. Liu, and Q. Li, "Application of gray relational analysis for chloride permeability and freeze-thaw resistance of high-performance concrete containing nanoparticles," Journal of Materials in Civil Engineering, vol. 23, no. 12, pp. 1760-1763, 2011.

[37] J. R. San Cristóbal, F. Correa, M. A. González et al., "A residual grey prediction model for predicting s-curves in projects," Procedia Computer Science, vol. 64, pp. 586-593, 2015.

[38] X.-W. Ren, Y.-Q. Tang, J. Li, and Q. Yang, "A prediction method using grey model for cumulative plastic deformation under cyclic loads," Natural Hazards, vol. 64, no. 1, pp. 441-457, 2012.

[39] K. C. P. Wang and Q. Li, "Pavement smoothness prediction based on fuzzy and gray theories," Computer-Aided Civil and Infrastructure Engineering, vol. 26, no. 1, pp. 69-76, 2011.

[40] S. Sahoo, A. Dhar, and A. Kar, "Environmental vulnerability assessment using grey analytic hierarchy process based model," Environmental Impact Assessment Review, vol. 56, pp. 145-154, 2016.

[41] B.-J. Qiu, J.-H. Zhang, Y.-T. Qi, and Y. Liu, "Grey-theory-based optimization model of emergency logistics considering time uncertainty," PLoS ONE, vol. 10, no. 9, Article ID e0139132, 2015.

[42] B. Twala, "Extracting grey relational systems from incomplete road traffic accidents data: the case of Gauteng Province in South Africa," Expert Systems, vol. 31, no. 3, pp. 220-231, 2014.

[43] B. Zeng, G. Chen, and S.-F. Liu, "A novel interval grey prediction model considering uncertain information," Journal of the Franklin Institute, vol. 350, no. 10, pp. 3400-3416, 2013.

[44] C. Li, J. Qin, J. Li, and Q. Hou, "The accident early warning system for iron and steel enterprises based on combination weighting and Grey Prediction Model GM $(1,1)$," Safety Science, vol. 89, pp. 19-27, 2016.
[45] K. Yan, D. Ge, L. You, and X. Wang, "Laboratory investigation of the characteristics of SMA mixtures under freeze-thaw cycles," Cold Regions Science and Technology, vol. 119, pp. 68-74, 2015.

[46] H. Y. Katman, M. R. Ibrahim, M. R. Karim, S. Koting, and N. S. Mashaan, "Effect of rubberized bitumen blending methods on permanent deformation of SMA rubberized asphalt mixtures," Advances in Materials Science and Engineering, vol. 2016, Article ID 4395063, 14 pages, 2016.

[47] Z. Chunxiu and T. Yiqiu, "Study on anti-icing performance of pavement containing a granular crumb rubber asphalt mixture," Road Materials and Pavement Design, vol. 10, pp. 281-294, 2009.

[48] AASHTO, American Association of State Highway and Transportation Officials, American Association of State Highway and Transportation Officials, 2006.

[49] H. Xu, W. Guo, and Y. Tan, "Internal structure evolution of asphalt mixtures during freeze-thaw cycles," Materials and Design, vol. 86, pp. 436-446, 2015.

[50] O. Keleştemur, S. Yildiz, B. Gökçer, and E. Arici, "Statistical analysis for freeze-thaw resistance of cement mortars containing marble dust and glass fiber," Materials and Design, vol. 60, pp. 548-555, 2014.

[51] A. M. Bagirov, A. Mahmood, and A. Barton, "Prediction of monthly rainfall in Victoria, Australia: clusterwise linear regression approach," Atmospheric Research, vol. 188, pp. 20-29, 2017.

[52] A. K. Yadav and S. S. Chandel, "Identification of relevant input variables for prediction of 1-minute time-step photovoltaic module power using artificial neural network and multiple linear regression models," Renewable and Sustainable Energy Reviews, 2017.

[53] J. J. Cannon, T. Kawaguchi, T. Kaneko, T. Fuse, and J. Shiomi, "Understanding decoupling mechanisms of liquid-mixture transport properties through regression analysis with structural perturbation," International Journal of Heat and Mass Transfer, vol. 105, pp. 12-17, 2017. 

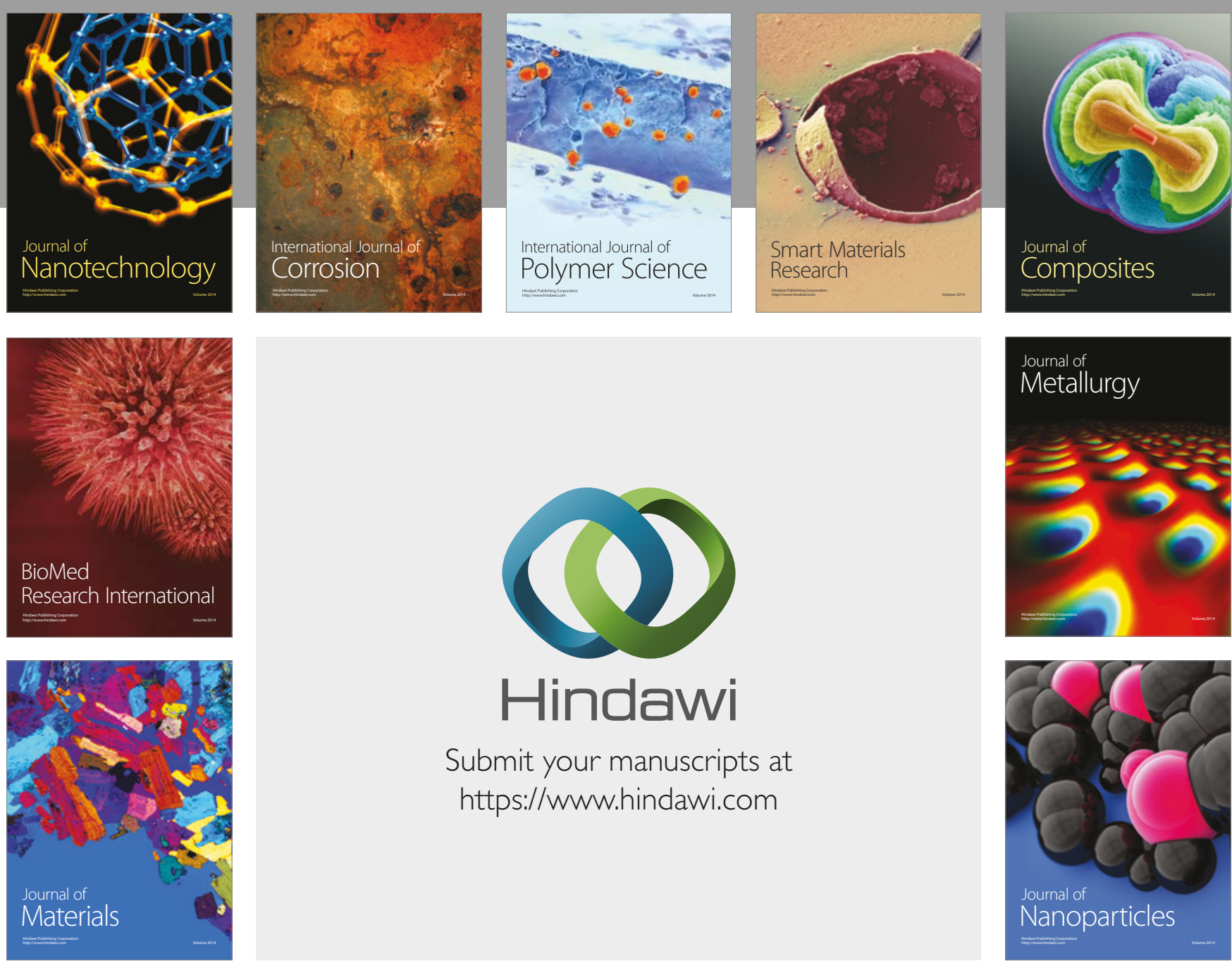

\section{Hindawi}

Submit your manuscripts at

https://www.hindawi.com
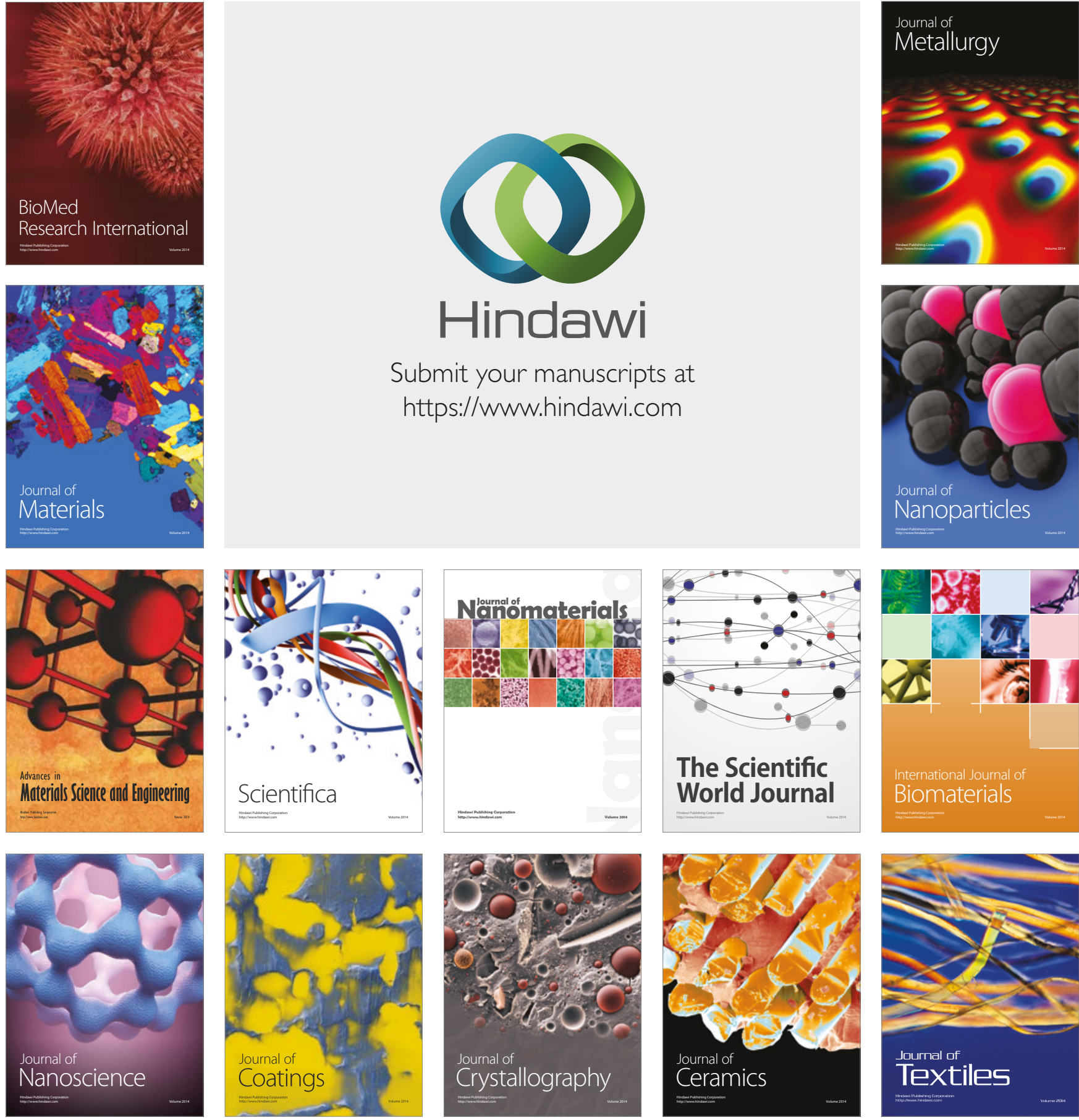

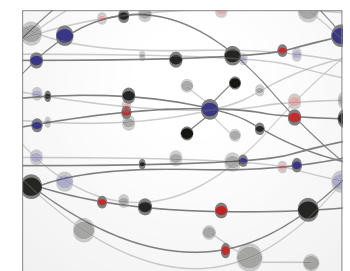

The Scientific World Journal
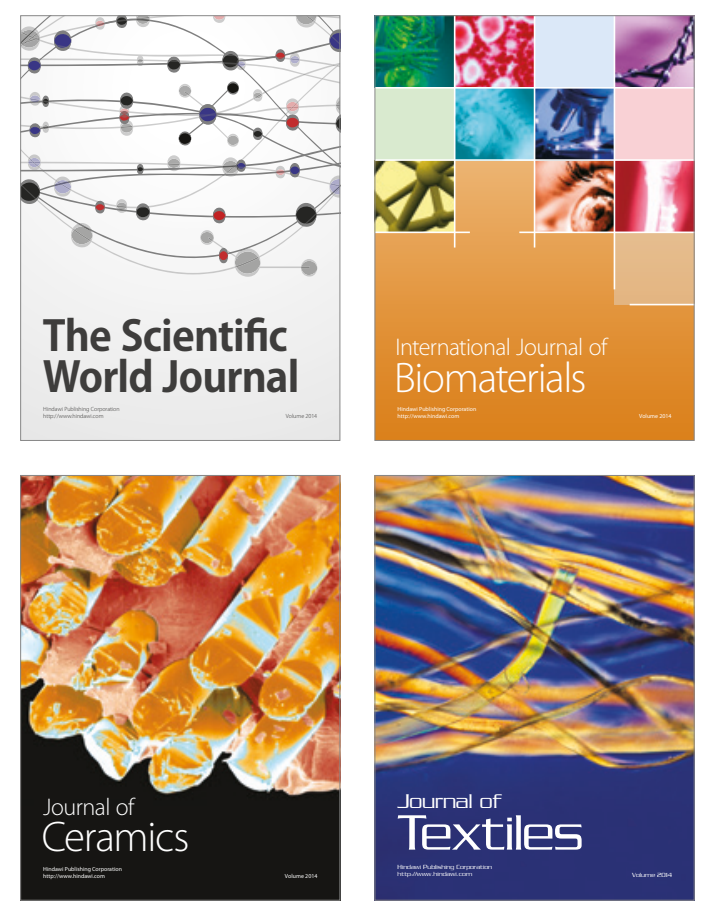